NBER WORKING PAPER SERIES

\title{
DIFFERENCES OF OPINION, RATIONAL ARBITRAGE AND MARKET CRASHES
}

\author{
Harrison Hong \\ Jeremy C. Stein
}

Working Paper 7376

http://www.nber.org/papers/w7376

\section{NATIONAL BUREAU OF ECONOMIC RESEARCH}

1050 Massachusetts Avenue

Cambridge, MA 02138

October 1999

We would like to thank the National Science Foundation and the Finance Research Center at MIT for financial support, and seminar participants at Cornell, MIT, the NBER (Behavioral Finance and Asset Pricing Groups), and Tulane, as well as Olivier Blanchard and Greg Duffee, for helpful comments and suggestions. The views expressed herein are those of the authors and not necessarily those of the National Bureau of Economic Research.

1999 by Harrison Hong and Jeremy C. Stein. All rights reserved. Short sections of text, not to exceed two paragraphs, may be quoted without explicit permission provided that full credit, including $\mathcal{O}$ notice, is given to the source. 
Differences of Opinion, Rational

Arbitrage and Market Crashes

Harrison Hong and Jeremy C. Stein

NBER Working Paper No. 7376

October 1999

JEL No. G12, G14

\section{ABSTRACT}

We develop a theory of stock-market crashes based on differences of opinion among investors. Because of short-sales constraints, bearish investors do not initially participate in the market and their information is not revealed in prices. However, if other, previously-bullish investors have a change of heart and bail out of market, the originally-more-bearish group may become the marginal "support buyers", and hence more will be learned about their signals. Thus accumulated hidden information tends to come out during market declines. The model helps explain a variety of stylized facts, including: 1) large movements in prices unaccompanied by significant news about fundamentals; 2) negative skewness in the distribution of market returns; and 3) increased correlation among stocks in a falling market. In addition, the model makes a distinctive out-of-sample prediction: that negative skewness will be most pronounced conditional on high trading volume.

Harrison Hong

Stanford Business School

Stanford University

Stanford, CA 94305

hghong@leland.stanford.edu
Jeremy C. Stein

Harvard Business School

Morgan 361

Boston, MA 02163

MIT Sloan School of Management and NBER

jstein@hbs.edu 


\section{Introduction}

In this paper, we address the question of why stock markets may be vulnerable to crashes. To get started, we need to articulate precisely what we mean by the word "crash". Our definition of a crash encompasses three distinct elements: 1) A crash is an unusually large movement in stock prices that occurs without a correspondingly large public news event; 2) moreover, this large price change is negative; and 3) a crash is a "contagious" market-wide phenomenon-i.e., it involves not just an abrupt decline in the price of a single stock, but rather a highly correlated drop in the prices of an entire class of stocks.

Each of these three elements of our definition can be grounded in a set of robust empirical facts. First, with respect to large price movements in the absence of public news, Cutler, Poterba and Summers (1989) document that many of the biggest post-war movements in the S\&P 500 index-most notably the stock-market break of October 1987-have not been accompanied by any particularly dramatic news events. Similarly, Roll $(1984,1988)$ and French and Roll (1986) demonstrate in various ways that it is hard to explain asset-price movements with tangible public information.

The second element of our definition is motivated by a striking empirical asymmetry-the fact that big price changes are more likely to be decreases rather than increases. In other words, stock markets melt down, but they don't melt up. This asymmetry can be measured in a couple of ways. One approach is to look directly at historical stock return data; in this vein it can be noted that of the ten biggest one-day movements in the S\&P 500 since 1947, nine were declines. ${ }^{1}$ More generally, a large literature documents that stock returns exhibit negative skewness, or, equivalently, "asymmetric volatility" - a tendency for volatility to go up with negative returns. ${ }^{2}$

Alternatively, since gauging the probabilities of extreme moves with historical data is inevitably plagued by "peso problems", one can look to options prices for more information on return distributions. Consider for example, the pricing of three-month S\&P 500 options

\footnotetext{
${ }^{1}$ Moreover, the one increase- of 9.10 percent on October 21, 1987-was right on the heels of the 20.47 percent decline on October 19, and arguably represented a working-out of the microstructural distortions created on that chaotic day (jammed phone lines, overwhelmed market-makers, unexecuted orders, etc.) rather than an independent, autonomous price change.

${ }^{2}$ Work on skewness and asymmetric volatility includes Pindyck (1984), French, Schwert and Stambaugh (1987), Campbell and Hentschel (1992), Nelson (1991), Engle and Ng (1993), Glosten, Jagannathan and Runkle (1993), Braun, Nelson and Sunier (1995), Duffee (1995a), Bekaert and Wu (1997) and Wu (1997).
} 
on January 27, 1999, when the Black-Scholes (1973) implied volatility was: i) 39.8 percent for out-of the money puts (strike $=80$ percent of current price); ii) 27.5 percent for atthe-money options; and iii) 17.5 percent for out-of the money calls (strike $=120$ percent of current price). These prices are obviously at odds with the lognormal distribution assumed in the Black-Scholes model, and can only be rationalized with an implied distribution that is strongly negatively skewed. As shown by Bates (1997), Bakshi, Cao and Chen (1997) and Dumas, Fleming and Whaley (1998), this pronounced pattern (often termed a "smirk") in index-option implied volatilities has been the norm since the stock-market crash of October $1987 .{ }^{3}$

The third and final element of our definition of crashes is that they are market-wide phenomena. That is, crashes involve a degree of cross-stock contagion. This notion of contagion corresponds to the empirical observation that the correlation of individual stock returns increases sharply in a falling market (see, e.g., Duffee (1995b)). Again, the results from historical data are corroborated by options prices. For example, Kelly (1994) writes that: "US equity index options exhibit a steep volatility (smirk) while single stock options do not have as steep a (smirk). One explanation...is that the market anticipates an increase in correlation during a market correction."

In our effort to develop a theory that can come to grips with all three of these empirical regularities, we focus on the consequences of differences of opinion among investors. ${ }^{4}$ We model differences of opinion very simply, by assuming that there are two investors, $A$ and $B$, each of whom gets a private signal about a stock's terminal payoff. As a matter of objective reality, each investor's signal contains some useful information. However, $A$ only pays attention to his own signal, even if that of $B$ is revealed to him in prices, and viceversa. Thus even without any exogenous noise trading, $A$ and $B$ will typically have different valuations for the asset.

In addition to investors $A$ and $B$, our model also incorporates a class of fully rational,

\footnotetext{
${ }^{3}$ These and other recent papers on options pricing find that one can better fit the index-options data by modelling volatility as a diffusion process that is negatively correlated with the process for stock returns. However, they do not address the question of what economic mechanism might be responsible for the negative correlation.

${ }^{4}$ Harris and Raviv (1993), Kandel and Pearson (1995) and Odean (1998) are among the recent papers that emphasize the importance of differences of opinion. However, the focus in these papers is primarily on understanding trading volume, not large price movements. See also Harrison and Kreps (1978) and Varian (1989) for related work.
} 
risk-neutral arbitrageurs. These arbitrageurs recognize that the best estimate of the stock's true value is obtained by averaging the signals of $A$ and $B$. However, the arbitrageurs may not always get to see both of these signals. This is because we assume-and all our results hinge crucially on this assumption-that investors $A$ and $B$ face short-sales constraints, and therefore can only take long positions in the stock.

To get a feel for the logic behind our model, imagine that at some time 1, investor $B$ gets a pessimistic signal, so that his valuation for the stock at this time lies well below $A$ 's. Because of the short-sales constraint, investor $B$ will simply sit out of the market, and the only trade will be between investor $A$ and the arbitrageurs. The arbitrageurs are rational enough to deduce that $B$ 's signal is below $A$ 's, but they cannot know exactly by how much. Thus the market price at time 1 impounds $A$ 's prior information but does not fully reflect $B$ 's time-1 signal.

Next, suppose that at time 2, investor $A$ gets a new positive signal. Since $A$ continues to be the more optimistic of the two, his new time- 2 signal is incorporated into the price, while $B$ 's pre-existing time-1 signal remains hidden.

Now contrast this with the situation where investor $A$ gets a bad signal at time 2 . Here things are more complicated, and it is possible that some of $B$ 's previously hidden time1 signal may be revealed at time 2 . Intuitively, as $A$ bails out of the market at time 2, arbitrageurs will learn something by observing if and at what price $B$ steps in and starts being willing to buy. For example, it may be that $B$ starts buying after the price drops by only 5 percent from its time- 1 value. In this case, the arbitrageurs learn that $B$ 's time-1 signal was not all that bad. But if $B$ doesn't step in even after the price drops by 20 percent, then the arbitrageurs must conclude that $B$ 's time-1 signal was more negative than they had previously thought. In other words, the failure of $B$ to offer "buying support" in the face of $A$ 's selling is additional bad news for the arbitrageurs, above and beyond the direct bad news that is inherent in $A$ 's desire to sell.

It is easy to see from this discussion how the model captures the first two elements in our definition of a crash. First, note that the price movement at time 2 may be totally out of proportion to the news arrival (i.e., the signal to $A$ ) that occurs at this time, since it may also reflect the impact of $B$ 's previously hidden signal. In this sense, we are quite close in spirit to Romer (1993), who makes the very insightful point that the trading process can 
cause the endogenous revelation of pent-up private information, and can therefore lead to large price changes based on only small observable contemporaneous news events.

Second-and here we differ sharply from Romer, whose model is inherently symmetricthere is a fundamental asymmetry at work in our framework. When $A$ gets a good signal at time 2 , it is revealed in the price, but nothing else is. However, when $A$ gets a bad signal at time 2 , not only is this signal revealed, but $B$ 's prior hidden information may come out as well. Thus more total information comes out when the market is falling, (i.e., when $A$ has a bad signal) which is another way of saying that the biggest observed price movements will be declines.

The one feature of our model that is not readily apparent from the brief discussion above is the one having to do with contagion, or increased correlation among stocks in a downturn. To get at this, we have to augment the story so that there are multiple stocks. This opens the possibility that a sell-off in one stock $i$ causes the release of pent-up information that is not only relevant for pricing that stock $i$, but also for pricing another stock $j$. Consequently, bad news tends to heighten the correlation among stocks. And interestingly, the price of stock $j$ may now move significantly at a time when there is absolutely no contemporaneous news about its own fundamentals.

In addition to fitting these existing stylized facts, the theory makes further distinctive predictions which have not yet been tested. These predictions have to do with the conditional nature of return asymmetries-i.e., the circumstances under which negative skewness in returns will the strongest. When the differences of opinion that set the stage for negative asymmetries are most pronounced, there tends to be abnormally high trading volume. Therefore, elevated trading volume should forecast increased negative skewness, both in the time series and in the cross-section.

Our theory of crashes can be thought of as "behavioral", in that it relies on less-than-fully rational behavior on the part of investors $A$ and $B$. Indeed, the differences of opinion that we model can be interpreted as a form of overconfidence, whereby each investor (incorrectly) thinks his own private signal is more precise than the other's. Or, alternatively, as in Hong and Stein (1999), the differences of opinion can be thought of as reflecting a type of bounded rationality in which investors are simply unable to make inferences from prices. Of course, the usual critique that is applied to these sorts of models is: "what happens when 
one allows for rational arbitrage?" And, in fact, in most models in the behavioral genre, sufficiently risk-tolerant rational arbitrage tends to blunt or even eliminate the impact of the less-rational agents.

In contrast, our results go through even with rational risk-neutral arbitrageurs who can take infinitely long or short positions. This is because the interplay between the arbitrageurs and the less-rational investors is different than in, say, the noise-trader framework of DeLong et al (1990). In their setting, the less-rational traders have no information about fundamentals, and so the job of the arbitrageurs is just to absorb the additional risk that these noise traders create. In our model, the job of the arbitrageurs is more complicated, because while investors $A$ and $B$ are not fully rational, they do have access to legitimate private information that the arbitrageurs need. Thus infinite risk tolerance on the part of the rational arbitrageurs is not sufficient to make the model equivalent to one in which everybody behaves fully rationally. ${ }^{5}$

Of course, by making our arbitrageurs risk-neutral, we lose the ability to say anything about expected returns-all expected returns in our model are zero, and our implications are only for the higher-order moments of the return distribution. So unlike much of the behavioral finance literature, we do not attempt to speak to the large body of empirical evidence on return predictability. But it is interesting to note that while behavioral models have been used extensively to address the facts on predictability, as well as to explain trading volume, there has been very little serious effort (of which we are aware) to explain market crashes based on behavioral considerations. Ironically, all the best existing models of large price movements are, like Romer (1993), rational models. ${ }^{6}$ It is not much of an exaggeration to say that a state-of-the art behavioral explanation of a market crash is something along the lines of: "there was an abrupt change in investor sentiment."

The remainder of the paper is organized as follows. In Section II, we lay out the assumptions of our model. For simplicity, we consider the case where there is a single traded asset, which can be interpreted either as an individual stock or as the market portfolio. In Section III, we solve the model and flesh out its implications for the distribution of returns at different horizons. In Section IV, we briefly examine a couple of multiple-asset extensions, which

\footnotetext{
${ }^{5}$ The idea that arbitrageurs interact with a class of investors who have valuable information but who overweight this information is also central to Hong and Stein (1999).

${ }^{6}$ We discuss this "rational-crash" literature in detail below.
} 
allow us to address issues such as the potential for increased cross-stock correlations in a falling market. In Section $\mathrm{V}$ we discuss the link between our work and previous research on large price movements and/or return asymmetries. In Section VI we conclude by discussing how the theory's most distinctive out-of-sample empirical implications-those having to do with trading volume and conditional skewness-might be tested.

\section{The Model}

\section{A Timing and information structure}

Our model has four dates, which we label times $0,1,2$ and 3 . Initially, we consider the case where there is one "stock" that will pay a terminal dividend of $D$ at time 3 ; it should be stressed that this "stock" can equally well be thought of as the market portfolio. There are three potential traders in the stock: investors $A$ and $B$, and a group of competitive, risk-neutral rational arbitrageurs. Investors $A$ and $B$ are subject to short-sales constraints, but the arbitrageurs are not. ${ }^{7}$ One can interpret the short-sales constraints literally, but they might also be thought of as reflecting institutional restrictions-e.g., $A$ and $B$ might be mutual fund managers who, by virtue of their charters or regulation, are deterred from taking short positions. ${ }^{8}$

Investors $A$ and $B$ take turns getting informative signals about the terminal dividend. In particular, at time 1 , investor $B$ observes $S_{B}$, and next, at time 2 , investor $A$ observes $S_{A}$. From an objective rational perspective (that of the arbitrageurs), each of these signals is equally informative, as the terminal dividend is given by

$$
D=\left(S_{A}+S_{B}\right) / 2+\epsilon,
$$

where $\epsilon$ is a normally distributed shock with mean zero and variance normalized to one.

\footnotetext{
${ }^{7}$ Importantly, the model does not rest on the assumption that all or even most players are subject to the short-sales constraints. Indeed, the unconstrained risk-neutral arbitrageurs can be seen as representing the vast majority of buying power in the market. All that we really require is that some investors who have significant information be constrained.

${ }^{8} \mathrm{~A}$ relevant fact in this regard comes from Koski and Pontiff (1999). In a study of 679 equity mutual funds, they find that over 79 percent of the funds make no use whatsoever of derivatives (either futures or options). Given that derivatives are in many cases likely to be the most efficient means for implementing a short position, it would not appear that our approach is founded on an empirically unrealistic premise.
} 
As discussed in the Introduction, investors $A$ and $B$ each incorrectly believe that only their own signals are informative. This behavioral bias, which can be thought of as a form of overconfidence, induces a difference of opinion among the various agents in the model as to the value of the stock. So for example, when investor $A$ observes $S_{A}$ at time 2 , he believes that the terminal dividend has an expected value of $S_{A}$, irrespective of anything he might be able to infer about $S_{B}$. Assuming for simplicity that investor $A$ has CARA utility with a risk aversion coefficient of one, if he is offered the stock at time 2 at a price of $p_{2}$, his demand will, in light of the short-sales constraint, be given by

$$
Q_{A}\left(p_{2}\right)=\max \left[S_{A}-p_{2}, 0\right] .
$$

Here we are using the lower case notation $p_{2}$ to indicate that we are talking about a "trial" price that may be off the equilibrium path. ${ }^{9}$ We will reserve the upper case notation $P_{1}$ and $P_{2}$ to refer to the equilibrium prices that are realized at time 1 and time 2 , respectively; the significance of this distinction will become apparent shortly. Similarly, investor B's demand for the stock at time $t(t=1,2)$, if he is offered the stock at a price of $p_{t}$, will be $\mathrm{e}^{10}$

$$
Q_{B}\left(p_{t}\right)=\max \left[S_{B}-p_{t}, 0\right] .
$$

Prior to being realized at time $1, S_{B}$ is uniformly distributed on the interval $[0,2 V]$. Thus the rational expectation of $S_{B}$ as of time 0 is $\mathrm{E}_{0}\left[S_{B}\right]=V$. Prior to being realized at time $2, S_{A}$ is uniformly distributed on $[H, 2 V+H]$, so that $\mathrm{E}_{0}\left[S_{A}\right]=\mathrm{E}_{1}\left[S_{A}\right]=V+H$. Note that $V$ can be interpreted as a measure of the variance of the news that is received by the investors, while $H$ can be thought of as an ex ante measure of the heterogeneity of their opinions. In what follows, we assume that $0 \leq H \leq 2 V$. However, the bounds that we place on $H$ are not consequential for our results. We could also consider cases where we allow $H$ to exceed $2 V$, but this would add little to the analysis. Alternatively, we could be more symmetric, allowing for both positive and negative values of $H$-with the negative values corresponding to investor $B$ being ex ante more bullish than investor $A$. But nothing interesting happens when $H$ is negative. ${ }^{11}$

\footnotetext{
${ }^{9}$ We are treating $A$ and $B$ as price-takers. So it may be more accurate to think of each of them as corresponding to a group of competitive investors who all get the same signal.

${ }^{10}$ For simplicity, we are assuming that investor $B$ 's demand for the stock at time 1 depends only on his expectation of the terminal dividend, and not on the price that he expects to prevail at time 2. This assumption is not at all critical for our results.

${ }^{11}$ Intuitively, what makes our endogenous-information-revelation mechanism work is that after the bearish
} 


\section{B The price-setting mechanism}

We now turn to the determination of prices at the various dates. Note that because of the risk-neutrality of the arbitrageurs, we can without loss of generality set the supply of the stock to zero. It is also easy to see that the price at time 0 is given by

$$
P_{0}=V+H / 2 .
$$

This is just the arbitrageurs' ex-ante expectation of the terminal dividend before either $A$ or $B$ have received their signals. But once these signals begin to be realized, at times 1 and 2 , the issue of price-setting becomes a bit more complicated, and we have to be clear about the mechanism that is used.

We assume the following set-up at times 1 and 2. Investors $A$ and $B$, along with the arbitrageurs, are all together in a room with an auctioneer. Any time the auctioneer announces a trial price $p_{t}$, the participants respond by calling out their demands. Because of the short-sales constraints, investors $A$ and $B$ only call out something if their demands are positive; otherwise they are silent. The arbitrageurs, who face no short-sales constraint, are free to call out either positive or negative demands. Importantly, the arbitrageurs are able to observe any demands called out by investors $A$ and $B$.

The auctioneer follows a simple mechanical rule, which could be carried out by a computer. He starts by announcing a "high" trial price, say $2 V+H$, which is known to be higher than anybody's highest possible valuation. At this high price, the net excess demand for the stock is certain to be negative. The auctioneer then gradually begins to adjust the price. His adjustment rule is that as long as the excess demand remains negative, he lowers the price. Conversely, if he ever reaches a point where the excess demand is positive, he raises the price. This process continues until the market clears-that is, until the auctioneer finds a price such that the excess demand for the stock is zero.

As will become clear below, this auction mechanism provides us with a simple way to determine a unique equilibrium price at each date. Moreover, the equilbrium will have the

investor gets his signal, there is another round of trade where more signals are received. Given that the model only has two trading periods, it is important to have at least some situations where the ex ante more bearish investor gets his signal at time 1 . This is what we accomplish by having $H$ be positive. In a model with many periods, it would almost always be the case that relatively bearish investors get some information before the last round of trade. 
intuitive property that whichever investor $(A$ or $B)$ has the more positive signal at a given date will be long the stock, and his signal will be fully revealed. In contrast, the investor with the less positive signal will not own any shares in equilibrium, and his signal may or may not be revealed in the course of the auction. Although it is obviously something of a modelling contrivance, we do not think that our auction scheme is too unrealistic. In fact, it resembles quite closely the opening procedures used in several major stock markets, including the Paris Bourse, the Toronto Exchange and the NYSE. ${ }^{12}$

\section{The rational-expectations benchmark}

Before solving the model with differences of opinion, we digress briefly and consider the benchmark case where all the players in the model are fully rational. In this benchmark case, investors $A$ and $B$, like the arbitrageurs, recognize that the best estimate of the terminal dividend (conditional on knowing $S_{A}$ and $\left.S_{B}\right)$ is given by $\left(S_{A}+S_{B}\right) / 2$, rather than just by their own private signals. This results in the following outcome:

Proposition 1 When investors $A$ and $B$ are fully rational, the short-sales constraint does not bind. Prices fully reflect all information as soon as it becomes available to investors:

$$
\begin{aligned}
& P_{1}=\left(V+H+S_{B}\right) / 2 ; \\
& P_{2}=\left(S_{A}+S_{B}\right) / 2 .
\end{aligned}
$$

Consequently, returns are symmetrically distributed at time 1 and time 2. Returns are also homoskedastic-i.e., they have the same variance at time 1 as at time 2.

To see the logic of the proof, consider time 1, and suppose that investor $B$ 's information has not yet come out during the auction process. This implies that investor $B$ 's estimate of the terminal dividend is lower than any trial price $p_{1}$ that has been announced. At the same time, any market-clearing price $P_{1}$ must equal the risk-neutral arbitrageurs' estimate of the terminal dividend. And the arbitrageurs recognize that investor $B$ is rational and strictly better informed than they are at time 1 . Thus as long as $S_{B}$ has not been revealed, the

\footnotetext{
${ }^{12}$ The Paris Bourse would seem to be especially close to what we have in mind: during a pre-opening period, trial clearing prices are transmitted to some traders along with information on excess demand at those prices, and the traders can revise their orders multiple times before a market clearing price is established. See Domowitz and Madhavan (1998) for details.
} 
arbitrageurs know that the trial price $p_{1}$ is too high, and the market cannot clear. Similar reasoning establishes that the market cannot clear at time 2 unless $S_{A}$ has been revealed.

Proposition 1 is significant because it highlights the key role that differences of opinion play in our model. The results on return asymmetries and heteroskedasticity that we obtain below are not driven solely by the short-sales constraint; rather the short-sales constraint must interact with the differences of opinion to generate anything interesting. ${ }^{13}$

\section{Solving the Model with Differences of Opinion}

\section{A Time 1: the potential for hidden information}

We now turn back to the situation where there are differences of opinion. Now it is possible that an investor's signal may not be revealed in equilibrium, if he is sufficiently pessimistic. Let us first examine what happens at time 1, when the only private information is held by investor $B$. We can distinguish two possible cases:

Case I: Investor $B$ 's information is revealed, in which case

$$
P_{1}=\left(V+H+S_{B}\right) / 2 .
$$

Case II: Investor $B$ 's information remains hidden, in which case

$$
P_{1}=(V+H) / 2+\mathrm{E}_{1}\left[S_{B} \mid \mathrm{NR}\right] / 2,
$$

where $\mathrm{E}_{1}\left[S_{B} \mid \mathrm{NR}\right]$ is the time-1 conditional expectation of $S_{B}$, given that $S_{B}$ has not been revealed.

When can Case II occur? Given our auction mechanism, a necessary condition for $S_{B}$ to remain hidden is that $S_{B} \leq P_{1}$. In words, investor $B$ 's valuation must not exceed the market clearing price, or otherwise he would have called out a non-zero demand during the auction, thereby tipping his signal to the arbitrageurs. Holding the arbitrageurs' conjectures fixed, the necessary condition becomes harder to satisfy the higher is $S_{B}$. This suggests that

\footnotetext{
${ }^{13}$ This feature distinguishes our model from that of Diamond and Verrecchia (1987), where short-sales constraints matter even in a setting where everybody is rational. Loosely speaking, the difference arises because our price-setting mechanism allows for more information-sharing among traders at a given point in time than theirs, which in turn gives the rationality assumption more bite.
} 
there will be a cutoff value of $S_{B}$-which we denote by $S_{B}^{*}$-such that if $S_{B}$ lies above $S_{B}^{*}$, the equilibrium must involve revelation of $S_{B}$.

It is easy to establish what the value of $S_{B}^{*}$ must be. If there is revelation for all values of $S_{B}>S_{B}^{*}$, then the expected value of $S_{B}$ conditional on no revelation, $\mathrm{E}_{1}\left[S_{B} \mid N R\right]$, must equal $S_{B}^{*} / 2$. This implies that the price in Case II is given by

$$
P_{1}=(V+H) / 2+S_{B}^{*} / 4
$$

But we can only be in Case II if $S_{B} \leq P_{1}$. So one solves for the cutoff $S_{B}^{*}$ by setting it equal to $P_{1}$, which gives us:

Lemma 1 Let the cutoff value for $S_{B}$ be

$$
S_{B}^{*}=2(V+H) / 3
$$

Then for all values of $S_{B}>S_{B}^{*}$, there must be revelation of $S_{B}-i . e$. , we must be in Case $I$.

It is worthwhile to map out specifically how the auction mechanism works in Case I, when $S_{B}>S_{B}^{*}$, and hence $S_{B}$ is revealed. There are two qualitatively distinct scenarios. In the first, $S_{B}$ is "very high"; in particular $S_{B}>(V+H)$, which means that investor $B$ 's valuation is higher even than the ex ante expectation of $A$ 's valuation. (Note that this can only occur if we make the assumption that $H<V$.) As the auctioneer starts to work the trial price down, initially all he hears are sell orders from the arbitrageurs, as the trial price is above everybody's valuation. When the auctioneer gets to a trial price $p_{1}=S_{B}$, investor $B$ calls out, revealing his signal. At this point, the arbitrageurs become fully informed. They recognize that the true value of the stock is $\left(V+H+S_{B}\right) / 2$, so at $p_{1}=S_{B}$, they continue to want to sell. Thus the price keeps dropping until it hits $\left(V+H+S_{B}\right) / 2$, at which point the market clears. Observe that in this scenario, the bullish investor $B$ is long the stock in equilibrium.

In the second scenario of Case I, $S_{B}$ is only "moderately high"; i.e., $S_{B}^{*}<S_{B} \leq(V+H)$. Now the auctioneer's trial price can drop further with investor $B$ staying silent. For any trial price $p_{1}$ in this silent region, and below $2 \mathrm{~V}$, the arbitrageurs' conditional estimate of the terminal payoff is just $(V+H) / 2+E\left[S_{B} \mid S_{B} \leq p_{1}\right] / 2=(V+H) / 2+p_{1} / 4$. This implies that the longer investor $B$ stays quiet in the face of dropping trial prices, the lower the 
arbitrageurs' estimate drops. Moreover, as long as this estimate remains below the trial price of $p_{1}$, the risk-neutral arbitrageurs have infinite negative demand. This in turn causes the auctioneer to move $p_{1}$ down further. When $p_{1}$ hits $S_{B}$, investor $B$ calls out, thereby revealing his signal. This is good news for the arbitrageurs-they learn that they are in Case I rather than Case II- so their estimate of the value jumps discretely, to $\left(V+H+S_{B}\right) / 2$. As a result, there is now positive excess demand, and the auctioneer has to raise the price back up to meet the arbitrageurs' new estimate, at which point the market finally clears.

A subtle point about this second scenario is that $S_{B}$ is revealed through the auction process even though, in equilibrium, investor $B$ ends up holding no shares. This is because in this scenario, the trial price at some point necessarily falls below the ultimate equilibrium price, causing investor $B$ to call out a demand and reveal his signal.

If $S_{B} \leq S_{B}^{*}$, however, $S_{B}$ can remain concealed. More precisely, given our auction mechanism, we can show:

Lemma 2 For all values of $S_{B} \leq S_{B}^{*}$, the unique equilibrium involves the "pooling" outcome of Case II, where $S_{B}$ remains hidden, and where

$$
P_{1}=(V+H) / 2+S_{B}^{*} / 4=2(V+H) / 3 .
$$

The ex ante probability of winding up in this pooling equilibrium is $(V+H) / 3 V$. That is, pooling is more likely when there is more ex ante heterogeneity in opinions, as measured by the parameter $H$.

In this case, the auction proceeds as follows. The auctioneer works the trial price $p_{1}$ down, as before. But this time, before $p_{1}$ falls to $S_{B}$, and hence before investor $B$ calls out, the trial price hits $S_{B}^{*}$. At $p_{1}=S_{B}^{*}$, the arbitrageurs' estimate of value, $(V+H) / 2+p_{1} / 4$, equals the prevailing trial price. So the market clears before investor $B$ ever gets in.

It should be pointed out that the uniqueness of the pooling equilibrium for $S_{B} \leq S_{B}^{*}$ is a consequence of our assumptions about the adjustment rule followed by the auctioneer. To see why, suppose the auctioneer was not restricted to adjusting prices gradually, but instead could discontinuously announce a trial price of zero. At this point, investor $B$ would always call out a demand, for any value of $S_{B}$. That is, $S_{B}$ would always be revealed, no matter how low. Thus our auction mechanism, while it is arguably reasonable, is also critical to 
establishing the central feature of our model-that some information may remain hidden at time 1 .

\section{B Time 2: previously hidden information may be revealed}

The bottom line from our analysis of time 1 is that if $S_{B}$ is low enough, it may not be immediately revealed. Now we move to time 2. The primary goal here is to show that a low draw of investor $A$ 's signal, $S_{A}$, may cause further information on $S_{B}$ to come out. So naturally, much of our focus will be on that branch of the time-1 tree where we were in Case II, and $S_{B}$ was hidden. However, because we ultimately want to be able to provide a complete description of the distribution of returns at both time 1 and time 2 , we also need to fill in what happens along the less interesting branch of the tree where there was no hidden information at time 1-i.e., where we were previously in Case I. This is where we begin.

\section{B.1 Case I: $B$ 's signal was revealed at time 1}

If $S_{B}$ has already been revealed, the analysis at time 2 is very similar to that at time 1 . If the signal of investor $A, S_{A}$, is relatively high, it will also be revealed at time 2 . However, if it is sufficiently low, it may remain hidden. In particular we can show:

Lemma 3 Assume that $S_{B}$ has been revealed at time 1. Let the cutoff value for $S_{A}$ be

$$
S_{A}^{*}=\left(2 S_{B}+H\right) / 3
$$

For all values of $S_{A}>S_{A}^{*}, S_{A}$ is also revealed at time 2, and

$$
P_{2}=\left(S_{A}+S_{B}\right) / 2
$$

We call this Case I.A.

Lemma 4 Assume that $S_{B}$ has been revealed at time 1. If $S_{A} \leq S_{A}^{*}$, equilibrium at time 2 involves a pooling outcome where $S_{A}$ remains hidden, and where

$$
P_{2}=S_{B} / 2+\left(H+S_{A}^{*}\right) / 4=\left(2 S_{B}+H\right) / 3
$$

We call this Case I.B. 


\section{B.2 Case II: $B$ 's signal was hidden at time 1}

If $S_{B}$ has not yet been revealed, the analysis at time 2 is more interesting; this is where the heart of our model lies. The results in this case can be characterized by four lemmas. These four lemmas, which are proven in the appendix, collectively provide a complete characterization of the possible time- 2 outcomes for all parameter values.

First, if investor $A$ gets good news at time 2-that is, if $S_{A}$ turns out to be above its ex ante expectation-no further information on $S_{B}$ comes out. That is,

Lemma 5 Assume that $S_{B}$ was hidden at time 1. If $S_{A} \geq(V+H)$, then $S_{A}$ is revealed, and $S_{B}$ continues to pool below the old time-1 cutoff of $S_{B}^{*}$. The price in this case is given by

$$
P_{2}=S_{A} / 2+S_{B}^{*} / 4=S_{A} / 2+(V+H) / 6 .
$$

We call this Case II.A.

This makes intuitive sense; given that investor $B$ was too pessimistic relative to the prior on $S_{A}$ to get into the market and tip his signal at time 1, he certainly won't get in at time 2 if $A$ becomes even more optimistic and the gap between $A$ 's and $B$ 's valuations widens.

Second, if investor $A$ gets a bad signal at time 2, some further information on $S_{B}$ will come out. Importantly, however, this need not imply that $S_{B}$ is fully revealed. Instead, it is possible that $S_{B}$ will still pool, but inside a lower portion of its support. That is, it may be learned that $S_{B} \leq S_{B}^{* *}$, where $S_{B}^{* *}$ is a new cutoff level that is below $S_{B}^{*}$. This clearly represents a sharpening of the market's information on $S_{B}$, but it is not total revelation. Moreover, in this setting, one can meaningfully talk about "how much more" information on $S_{B}$ has come out-the lower is the new cutoff $S_{B}^{* *}$, the more has been learned. More precisely, we have

Lemma 6 Assume that $S_{B}$ was hidden at time 1, and also that $S_{A}<(V+H)$. Let the new cutoff

$$
S_{B}^{* *}=2 S_{A} / 3
$$

If $S_{B} \leq S_{B}^{* *}$, then $S_{A}$ is revealed, and $S_{B}$ pools below the new cutoff of $S_{B}^{* *}$. The price in this case is given by

$$
P_{2}=S_{A} / 2+S_{B}^{* *} / 4=2 S_{A} / 3 .
$$


We call this Case II.B.

Thus, if $S_{B}$ is small enough relative to $S_{A}$, it may still remain partially hidden at time 2 . On the other hand, if $S_{B}$ exceeds the new cutoff $S_{B}^{* *}$, it will be fully revealed. In fact there are two distinct scenarios in which $S_{B}$ is fully revealed. First, $S_{B}$ may be fully revealed while $S_{A}$ is hidden below a cutoff value of $S_{A}^{*}$ :

Lemma 7 Assume that $S_{B}$ was hidden at time 1, and also that $S_{A}<(V+H)$. As in Lemma 3, let the cutoff on $S_{A}$ be

$$
S_{A}^{*}=\left(2 S_{B}+H\right) / 3
$$

If $S_{A} \leq S_{A}^{*}$, and simultaneously $S_{B}>H$, then $S_{A}$ pools below $S_{A}^{*}$, while $S_{B}$ is fully revealed. The price in this case is given by

$$
P_{2}=S_{B} / 2+\left(H+S_{A}^{*}\right) / 4=\left(2 S_{B}+H\right) / 3
$$

We call this Case II. $\boldsymbol{C}$

Alternatively, both $S_{B}$ and $S_{A}$ can be revealed.

Lemma 8 Assume that $S_{B}$ was hidden at time 1. For any parameter values not already covered in Lemmas 5-7, both $S_{A}$ and $S_{B}$ are fully revealed at time 2. The price in this case is given by

$$
P_{2}=\left(S_{A}+S_{B}\right) / 2
$$

We call this Case II.D

The key point that emerges from the analysis is that, holding fixed the actual realization of $S_{B}$, more information on $S_{B}$ comes out the lower is $S_{A}$. This shows up in two ways. First, for a lower $S_{A}, S_{B}$ is more likely to be fully revealed. Second, even if it is not fully revealed, a lower value of $S_{A}$ implies that $S_{B}$ will remain hidden in a smaller portion of the lower support of its distribution.

We think that this feature of the model-the time-2 link between the realization of $S_{A}$ and the amount of new information that comes out on $S_{B}$-best embodies the central economic intuition that we are trying to capture. Essentially, our story is one in which a change 
of heart on the part of a previously-optimistic investor $(A)$ tests the resolve of another previously-sidelined investor $(B)$. The extent to which $B$ is willing to step in and offer buying support as $A$ bails out of the market is important data to the arbitrageurs. And the more completely $A$ bails, the more informative is the experiment conducted on the ostensible support buyers.

Figure 1 provides a compact illustration of all of our results to this point. It shows how the entire parameter space can be partitioned into six regions, corresponding to our Cases I.A, I.B, II.A, II.B, II.C, and II.D. Having done this partitioning-and knowing the equilibrium prices $P_{1}$ and $P_{2}$ that arise in each region-we can now make a variety of statements about the distributional properties of returns. For example, as we will demonstrate shortly, it is a straightforward task to compute the skewness of returns at various horizons, simply by taking the appropriate integrals over the different regions.

\section{Implications for return asymmetries at different horizons C.1 Asymmetries in "big moves"}

One simple, non-parametric way of thinking about asymmetries in the distribution of extreme returns is to calculate the largest possible moves-either up or down-that can occur at times 1 and 2. Consider time 1 first, and define the time- 1 return

$$
R_{1}=P_{1}-P_{0}
$$

Given our earlier results, it is easy to show that the biggest possible up-move at time 1, which we denote by $B I G^{U}\left(R_{1}\right)$, equals $V / 2$. This occurs when $S_{B}$ attains its highest value, and is fully revealed at time 1 . In contrast, the biggest possible down-move (in absolute value terms), $B I G^{D}\left(R_{1}\right)$, is given by $V / 3-H / 6$, which is strictly smaller than $B I G^{U}\left(R_{1}\right)$. Down-moves are less extreme at time 1 because if $S_{B}$ is very low, it is not fully revealed. Thus the asymmetry at time 1 is the opposite of what we are looking for-it suggests that the largest price movements will be increases, not decreases. Again, this is a direct consequence of the fact that bad news is hidden at time 1 .

Next, consider returns at time 2,

$$
R_{2}=P_{2}-P_{1} \text {. }
$$


As before, the biggest possible up-move, now denoted $B I G^{U}\left(R_{2}\right)$, equals $V / 2$. This reflects the highest possible realization of $S_{A}$, and the observation that when $S_{A}$ embodies good news, no further information on $S_{B}$ comes out. But now the biggest possible down-move, $B I G^{D}\left(R_{2}\right)$, is given by $2 V / 3$, which is strictly larger than $B I G^{U}\left(R_{2}\right)$. The reason the downmove can be more extreme is that it represents not only the full revelation of the lowest

possible $S_{A}$, but also further news about $S_{B}$, a piece of information which had been hidden from the market before time 2 .

Thus while returns at time 1 are suggestive of a positive asymmetry in the distribution, returns at time 2 are suggestive of a negative asymmetry. Moreover, the effect at time 2 is in a sense stronger, because the variance of returns at this time is greater. One way to express this is as follows:

Proposition 2 Taking into account both $R_{1}$ and $R_{2}$, the overall largest possible one-period return occurs on a down-move.

So, in an unconditional sense, it is indeed accurate to say that the distribution of extreme returns is characterized by a negative asymmetry-the biggest movements in the stock price will be decreases. This property of the model corresponds closely to the historical facts discussed in the Introduction.

\section{C.2 Skewness}

An alternative way to measure asymmetries in the return distribution is to calculate the skewness, or third moment of the distribution. As mentioned earlier, these skewness calculations are conceptually straightforward, though they involve fairly laborious integration. With the help of the computer program Mathematica, we are able to solve everything in closed form, and the results that we report below are based on the properties of these closed-form solutions. All details are in the appendix.

Again, we begin by considering the properties of the time-1 return, $R_{1}$. Analogous to our result with big moves, this return is positively skewed:

Lemma 9 For all values of $H$ and $V, \mathrm{E}\left[R_{1}^{3}\right] \geq 0$.

Moving to the time- 2 return, $R_{2}$, we find that things are a little more subtle. Conditional on $S_{B}$ having been hidden at time $1, R_{2}$ is indeed negatively skewed; this is where the 
intuiton from our big-moves analysis carries over directly. But it turns out that conditional on $S_{B}$ having been revealed at time $1, R_{2}$ is actually slightly positively skewed, for exactly the same reasons that $R_{1}$ is positively skewed-there may be some hiding of bad news, in this case bad news about $S_{A}$. (This positive skewness effect at time 2 comes from Case I.B.) Putting it all together, it turns out that, from an unconditional perspective, $R_{2}$ will be negatively skewed for all but the smallest values of $H$. More precisely, we have:

Lemma 10 Conditional on being in Case II, E $\left[R_{2}^{3} \mid\right.$ Case II $]<0$. Conditional on being in Case $I, \mathrm{E}\left[R_{2}^{3} \mid\right.$ Case $\left.\mathrm{I}\right]>0$. Unconditionally, $\mathrm{E}\left[R_{2}^{3}\right]$ is monotonically decreasing in the ratio $H / V$, and is negative for values of $H / V>.38$.

Of course, from an empirical perspective, it is more helpful to be able to make statements that do not depend on whether we take the perspective of time 1 or time 2 . In this spirit, we have:

Proposition 3 Define the overall unconditional skewness of short-horizon returns to be

$$
\mathrm{E}\left[R_{s}^{3}\right]=\frac{\mathrm{E}\left[R_{1}^{3}\right]+\mathrm{E}\left[R_{2}^{3}\right]}{2} .
$$

Our model has the property that $\mathrm{E}\left[R_{s}^{3}\right]<0$ for values of $H / V>1.69$.

Thus one of our central results is that short-horizon returns will, in an unconditional sense, be negatively skewed as long as there is enough ex ante heterogeneity in investors' opinions-i.e., as long as $H$ is large enough relative to $V$. Figure 2 illustrates the results of Lemmas 9 and 10, along with those of Proposition 3, showing how our various conditional and unconditional measures of short-horizon skewness vary with the ratio $H / V$.

To see intuitively why a high value of $H / V$ necessarily leads to negative skewness, consider the limiting situation where $H=2 V$. As we saw earlier, (Lemma 2) in this situation Case I disappears, and we are always in Case II, where $S_{B}$ is hidden at time 1. Consequently, prices do not move at all at time 1, so the positive skewness in time-1 returns from Lemma 9 drops out of the picture. All we are left with is the negative Case-II skewness at time 2 from Lemma 10.

It is useful to pause and ask why these results for skewness appear to be less decisive than those for big moves. Recall that with regard to big moves, we have the sharp conclusion 
that the largest possible move is always a decline, irrespective of the value of $H$. In contrast, with skewness, it seems that we need to put some restrictions on $H / V$ to get a clear-cut negative asymmetry.

This divergence reflects the fact that our model embodies two competing effects: a hiding-of-bad-news effect at time 1 that gives rise to a positive asymmetry; and a revelationof-news effect at time 2 that generates a negative asymmetry. The latter effect always dominates when the metric is big moves, but not necessarily when the metric is skewness, since skewness is in part influenced by returns that are not as far out in the tails of the distribution. To put it another way: we could in principle calculate higher-order odd moments of the return distribution-e.g. the fifth moment, the seventh moment, etc. These higher-order moments would be more heavily influenced by the action far out in the tails, and we conjecture that they would be more likely to be unconditionally negative at short horizons, for a wider range of values of $H / V$. Nevertheless, the concept of skewness is still an attractive one to focus on, since it is intuitive, easy to calculate (in our model), and allows us to map our findings into the large body of existing evidence that is based on this parametric measure.

In this spirit, another empirically-relevant thought experiment is to ask how skewness varies with the return horizon. We begin by defining a scaled measure of medium-horizon returns:

$$
R_{m}=\left(R_{1}+R_{2}\right) / \sqrt{2}
$$

The measure is scaled so that, in the rational-expectations benchmark, medium-horizon returns have the same variance as short-horizon returns; this sort of adjustment is necessary if we are to make meaningful comparisons of skewness across horizons. ${ }^{14}$ With the definition in hand, we can establish the following:

Proposition 4 For values of $H / V>1.84, \mathrm{E}\left[R_{m}^{3}\right]>\mathrm{E}\left[R_{s}^{3}\right]$. That is, medium-horizon skewness is less negative than short-horizon skewness when there are sufficiently large differences of opinion.

This result is driven by the following simple logic. As we lengthen the horizon over which returns are calculated, the potential for prices to move very sharply downward in a

\footnotetext{
${ }^{14}$ Without the scaling, there would be a strong tendency for longer-horizon returns, due to their greater variance, to have higher raw third moments.
} 
short interval (between time 1 and time 2) carries less weight, and therefore contributes less to negative skewness. Proposition 4 also squares nicely with the available evidence. For example, Bakshi, Cao and Chen (1997) and Derman (1999) find that the magnitude of the "smirk" in S\&P 500 index-option implied volatilities-the extent to which implied volatilities for out-of-the-money puts exceed those for out-of-the-money calls-is a decreasing function of the maturity of the options. Thus the options market is suggesting that negative return skewness in the S\&P 500 index diminishes with the horizon over which returns are measured.

\section{C.3 Trading volume and conditional skewness}

Although we have not emphasized it to this point, our model-like any model incorporating differences of opinion-has straightforward implications for trading volume. ${ }^{15}$ Simply put, when the gap between $A$ 's and $B$ 's valuations is larger at time 1 , there will tend to be more turnover. But since it is divergence of opinion at time 1 that leads to information being hidden and thereby sets the stage for the negative asymmetries in returns at time 2 , we also have a more novel result about conditional skewness: that time-1 trading volume forecasts the degree of negative skewness at time 2 .

To show more clearly why this is so, we consider a situation where $H>V .{ }^{16}$ We continue to assume that, as of time 0 , investors $A$ and $B$ have no initial endowment of the stock. Now let us ask what the trading volume is at time $1 .{ }^{17} A$ 's valuation of the stock at time 1 is simply his prior, $V+H$. B's valuation at time 1 is $S_{B}$. By virtue of the assumption that $H>V$, it follows that $A$ 's time-1 valuation is always higher than $B$ 's. Or said differently, $A$ 's valuation always lies above the market price of $P_{1}$, while $B$ 's valuation always lies below the market price. Hence $A$ is a buyer of stock (from the supply initially held by the arbitrageurs) while $B$ sits out of the market in equilibrium. So trading volume at time 1 can be completely summarized by the amount of stock that investor $A$ buys from the arbitrageurs.

Clearly, as long as $A$ is risk-averse, the amount that he buys will be an increasing function

\footnotetext{
${ }^{15}$ See, e.g., Harris and Raviv (1993), Kandel and Pearson (1995), and Odean (1998) for other models where differences of opinion drive trading volume.

${ }^{16}$ This parametric restriction simplifies the analysis but is not strictly necessary for the results that follow.

${ }^{17}$ Implicitly, we are assuming that $A$ and $B$ are not active in the market at time 0 , and that prices at this time are set (without any trading volume) by the arbitrageurs, who all agree on what the stock is worth ex ante.
} 
of the difference between his valuation and the market price. But this is the same thing as saying that $A$ buys more when $B$ has a lower signal $S_{B}$, since the market price $P_{1}$ is an increasing function of $S_{B}$. Thus we have:

Lemma 11 For $H>V$, trading volume at time 1 is a monotonically decreasing function of $S_{B}$. In particular, volume is strictly decreasing in $S_{B}$ for $S_{B}>S_{B}^{*}$ and attains a fixed maximum when $S_{B} \leq S_{B}^{*}$.

The implications for conditional skewness follow immediately from the lemma, since there can only be negative skewness in returns at time 2 if $S_{B}$ was not fully revealed at time 1-i.e., if $S_{B} \leq S_{B}^{*}$. In other words, there can only be negative skewness at time 2 if volume at time 1 was at its maximal level. Hence we have established:

Proposition 5 For $H>V$, the degree of negative skewness in time-2 returns is increasing in time-1 trading volume.

Proposition 5 can in principle be tested quite directly, using either time-series data on the aggregate market or data on individual stocks. Moreover, it would appear to be particularly useful in constructing a sharp, out-of-sample test of our theory. For while there are other models that can deliver negative asymmetries in returns, we are not aware of any that link these negative asymmetries to trading volume. We return to these issues in more detail below.

\section{Multiple Stocks and Contagion}

As discussed in the Introduction, there is evidence that individual stocks become more highly correlated with one another during market declines. This effect might be seen as indicative of a form of "contagion". We now discuss two variations on our model which illustrate how such an effect might arise.

\section{A Differences of opinion about the market factor}

One very easy way to generate increased cross-stock correlations in a market downturn is simply to argue that the returns on the market portfolio itself are, for some reason, 
negatively skewed. To be more precise, suppose that there are a large number of stocks and that the return on any given stock $i$ obeys a one-factor structure:

$$
R_{i}=R_{M}+Z_{i}
$$

where $R_{i}$ is the return on stock $i, R_{M}$ is the mean-zero return on the market factor, and $Z_{i}$ is a mean-zero idiosyncratic component that is independently and identically distributed across all stocks and independent of $R_{M}$.

For a given realization of $R_{M}$, we define $\hat{\sigma}_{i j}$ to be the average value (across all pairs of stocks) of the sample estimator of the covariance between the returns on any two stocks $i$ and $j$ :

$$
\hat{\sigma}_{i j}=\mathrm{E}\left[R_{i} R_{j} \mid R_{M}\right]
$$

Similarly, we define $\hat{\rho}_{i j}$ as the average value of the sample estimator of the correlation between the returns on any two stocks $i$ and $j$,

$$
\hat{\rho}_{i j}=\frac{\mathrm{E}\left[R_{i} R_{j} \mid R_{M}\right]}{\sqrt{\mathrm{E}\left[R_{i}^{2} \mid R_{M}\right] \mathrm{E}\left[R_{j}^{2} \mid R_{M}\right]}} .
$$

Note that both $\hat{\sigma}_{i j}$ and $\hat{\rho}_{i j}$ are random variables that depend on the realization of $R_{M}$.

In the appendix, we show that:

Proposition 6 If the return on the market factor is negatively skewed, $\mathrm{E}\left[R_{M}^{3}\right]<0$, then: i) $\operatorname{cov}\left(\hat{\sigma}_{i j}, R_{M}\right)<0$; and ii) $\operatorname{cov}\left(\hat{\rho}_{i j}, R_{M}\right)<0$.

The logic is straightforward. Conditional on a large movement in the market factor, individual stock returns are highly correlated-this is true even if the market factor is symmetrically distributed. But if the market factor is negatively skewed, then a large movement in it is more likely to occur on a decline. So on average, declines in the market factor correspond to increased values of $\hat{\sigma}_{i j}$ and $\hat{\rho}_{i j}$.

Therefore, if one assumes that the market factor is itself a traded asset, and that our model can be applied directly to it, the result about increased cross-stock correlations in a downturn will follow (at short horizons) so long as there are sufficient differences of opinion about the market factor that the conditions of Proposition 3 apply. In other words, if for the market factor, we have that $H / V>1.69$, then the market factor will exhibit negative skewness at short horizons, and cross-stock correlations will covary negatively with market returns. 


\section{B Idiosyncratic shocks to stock $i$ spill over to stock $j$}

In the preceding set-up, "contagion" arises through shocks to the market factor. That is, when there is a large drop in the market factor, all stocks tend to fall together. Although this approach is adequate for fitting the empirical facts about increased correlations in downturns, it may not quite capture the economic intuition that many people have about contagion. In this regard, perhaps a sharper definition of contagion is the idea that when there is bad firm-specific news about one stock $i$ at some time $t$, this causes a decline in the price of another stock $j$, even though the time- $t$ news has absolutely nothing to do with stock $j$ 's own fundamentals. ${ }^{18}$

To capture this idea, we consider an extension of our model where there are two stocks. Each stock has its own groups of investors, $A_{i}$ and $B_{i}$ for stock $i$, and analogously for stock $j$. Each stock also has its own group of arbitrageurs. To keep things simple, we focus on the polar case where for both stocks $H=2 \mathrm{~V}$.

The information structure is as follows. At time 1 , investor $B_{i}$ observes $S_{B, i}$, and at time 2 , investor $A_{i}$ observes $S_{A, i}$ (and analogously for stock $j$ ). The terminal dividends on the stocks are given by:

$$
\begin{aligned}
& D_{i}=\left(S_{A, i}+S_{B, i}+\gamma S_{B, j}\right) / 2+\epsilon_{i}, \\
& D_{j}=\left(S_{A, j}+S_{B, j}+\gamma S_{B, i}\right) / 2+\epsilon_{j},
\end{aligned}
$$

where $0<\gamma<1$. Thus the signals of the $A$ investors are completely firm-specific, while the signals of the $B$ investors contain some common information. In particular, the signal of investor $B_{i}$ is also informative about the terminal dividend on stock $j$.

The pricing of the two stocks proceeds as follows. First, note that because we have assumed that $H=2 \mathrm{~V}$, by Lemma 2 no information at all comes out for either stock at time 1-both $S_{B, i}$ and $S_{B, j}$ remain completely hidden at this time. Next, at time 2 , we assume that the markets for the two stocks are momentarily segmented. That is, the auction mechanisms

\footnotetext{
${ }^{18}$ This sharper definition appears in many accounts of emerging-markets crises, where the puzzle posed often goes something like this: Why is it that bad news that would seem to be specifically about the Russian economy not only devastates the Russian stock market but somehow leads to a drop in the Brazilian market as well? See, e.g., Kodres and Pritsker (1998) for a recent treatment and references to related work.
} 
for the two are run separately. Thus the auction for stock $i$ at time 2 only involves investors $A_{i}$ and $B_{i}$. This implies that prices at time 2 are given exactly as in Lemmas $5-8$, with the appropriate $i$ and $j$ subscripts.

However, right after the individual markets clear in segmented fashion at time 2, we insert another date, which we call time $2+$, at which point we allow the arbitrageurs to look at prices in both markets simultaneously, in order to update their estimates. Thus for example, if $S_{B, i}$ is fully revealed in the stock $i$ auction at time 2, it does not appear in the price of stock $j$ at time 2 , but it does immediately afterward, at time $2+.{ }^{19}$

It should now be apparent how there can be contagion in this framework. Suppose that at time 2 , there is no news about stock $j$-i.e., $S_{A, j}$ stays just at its prior value of $(V+H)-$ but there is bad firm-specific news about stock $i$, in the form of a low realization of $S_{A, i}$. Initially, in the segmented time-2 auctions, the price of stock $j$ is unchanged. However, the price of stock $i$ falls, and previously hidden information about $S_{B, i}$ is revealed, for exactly the same reasons as in the one-stock case. When we allow for information-sharing at time $2+$, this new information on $S_{B, i}$ is impounded into the price of stock $j$. So, remarkably, the price of stock $j$ moves even though there is absolutely no contemporaneous news about its own fundamentals. This in turn induces a correlation between the two stocks at a time when stock $i$ is falling.

As a consequence, this set-up also delivers increased comovements during market declines. To be specific, we define the price of stock $i$ at time $2+$ as $P_{i, 2+}$, and the corresponding two-period returns: ${ }^{20}$

$$
\begin{aligned}
& R_{i}=\left(P_{i, 2+}-P_{i, 0}\right), \\
& R_{M}=\left(R_{i}+R_{j}\right) / 2 .
\end{aligned}
$$

Here $R_{M}$ is the return on a "market portfolio" that is an equal-weighted combination of stocks $i$ and $j$. In addition, we define $\hat{\sigma}_{i j}$ to be the sample estimator of the covariance

\footnotetext{
${ }^{19}$ The momentary segmentation of the two markets before we allow full information-sharing at time $2+$ is just a modelling trick. We do it so as to keep the auctions for the two stocks separate, which greatly simplifies the analysis of equilibrium in terms of cutoff levels, etc. Indeed, it allows us to use all our earlier results from Lemmas 5-8 without any modification.

${ }^{20}$ Note that it is no longer meaningful to distinguish between one and two-period returns, since given our simplifying assumption that $H=2 \mathrm{~V}$, prices do not change at time 1.
} 
between the returns on stocks $i$ and $j$ :

$$
\hat{\sigma}_{i j}=R_{i} R_{j} .
$$

Note that now $\hat{\sigma}_{i j}$ is a random variable that depends on the realizations of both $R_{i}$ and $R_{j}$.

We prove in the appendix that:

Proposition 7 The covariance estimator for stocks $i$ and $j$ covaries negatively with the return on the market portfolio: $\operatorname{cov}\left(\hat{\sigma}_{i j}, R_{M}\right)<0$.

\section{Related Work}

In this section, we discuss the link between our theory and previous work that also focuses on either large price movements or return asymmetries. We divide this other work into three broad categories: 1) rational models with incomplete information aggregation; 2) volatility-feedback models; 3) behavioral stories.

\section{A Rational models with incomplete information aggregation}

One important class of theories shows how there can be large movements in asset prices in the absence of external news about fundamentals, even when all market participants are fully rational. Notable papers include Grossman (1988), Gennotte and Leland (1990), Jacklin, Kleidon and Pfleiderer (1992) and Romer (1993). ${ }^{21}$ All these papers share a common theme: investors are initially imperfectly informed about some important variable, which is not revealed to them in prices. However, the process of trading may eventually cause this information to come out, at which time prices can change sharply, even if no external news has arrived.

Although our model incorporates some less-than-fully-rational agents, it clearly draws heavily on the basic insights from this earlier work, particularly Romer (1993). Romer's model has the feature that traders start out not knowing the precision of each others' information. As shocks arrive, they update their estimates of this precision, which can be given the interpretation that each trader is learning about the elasticity of demand of other

\footnotetext{
${ }^{21}$ See Kleidon (1994) for a detailed review of this branch of the literature and further references.
} 
traders. This is broadly analogous to our idea of the arbitrageurs learning about the extent of "buying support" from investor $B$ as investor $A$ bails out of the market.

In spite of the similarities, however, there is one crucial distinction between our model and these others: ours is fundamentally asymmetric, producing larger downward price movements than upward ones. In contrast, all the logic in Romer (1993) is totally symmetric, so large up and down moves are equally likely. ${ }^{22}$ Somewhat more subtly, while the models of Grossman (1988), Gennotte and Leland (1990) and Jacklin et al (1992) have been used specifically to explain the stock-market crash of October 1987, this argument entails the additional assumption that market participants systematically underestimated the extent of portfolio insurance that was in place prior to the crash. While such a "one-bad-draw" type of assumption may be a perfectly reasonable way to rationalize a single given event, it is hard to use these sorts of models if the goal is to explain a pervasive tendency of markets to melt down, rather than melt up. In other words, if one runs these models over repeatedly, on average traders should be just as likely to overestimate as to underestimate the extent of portfolio insurance, so the long-run distribution should show just as many big up moves as big down moves. ${ }^{23}$

\section{B Volatility-feedback models}

Unlike the incomplete-information-aggregation theories, the volatility-feedback literature, which includes Pindyck (1984), French, Schwert and Stambaugh (1987), and Campbell and Hentschel (1992), is all about asymmetries in returns. The basic idea is a simple one. When a large piece of news arrives, this signals that market volatility has gone up. Assuming that market volatility commands a risk premium, the positive effect of a large piece of good news is damped, as the increased-risk-premium effect partially offsets the direct good-news effect. Conversely, the negative effect of a large piece of bad news is amplified. The result is

\footnotetext{
${ }^{22}$ A recent paper that extends Romer (1993) is Coval and Hirshleifer (1998). Their model can produce certain conditional patterns in skewness-i.e., negative skewness after price increases, and positive skewness after price declines. However, it appears that, like in Romer's model, there is no unconditional skewness, and hence no prediction that large down moves are ex ante more likely than large up moves.

${ }^{23} \mathrm{~A}$ similar observation can be made about other, more microstructure-oriented accounts of the October 1987 crash, including those in the Brady Report (1988) or Greenwald and Stein (1991). These accounts emphasize how unusually large selling volume overwhelmed market-making capacity, thereby exacerbating the decline in prices. But their inherently symmetric logic would seem to suggest that if there were ever comparable buying volume, one should get an equal-sized increase in prices.
} 
that even if the process driving news is symmetric, returns-particularly the returns on the market portfolio-will be negatively skewed.

One important difference between our approach and the volatility-feedback models is that they are set in a representative-agent framework, and hence are completely silent on trading volume, while our focus on differences of opinion leads very naturally to a linkage between volume and the conditional intensity of negative skewness. Moreover, from the perspective of our interest in crashes, a weakness of the volatility-feedback class of models is that, like any rational model with perfect information, they require very large doses of external public news if they are to generate very large price movements. ${ }^{24}$ Thus these models $^{2}$ may be more helpful in thinking about skewness in "typical" stock returns, as opposed to rare tail events; certainly this has been the focus of the empirical literature that has adopted the volatility-feeback approach. ${ }^{25}$

So to give an oversimplified summary, the incomplete-information-aggregation models and the volatility-feedback models each get at some of the elements of our definition of a crash. But none get at all the elements simultaneously. The incomplete-informationaggregation models are good for producing big price movements without big news, but not for delivering asymmetries. Conversely, the volatility-feedback models generate asymmetries, but they do not leave open a role for trading volume. Nor is it clear that they are helpful for thinking about really dramatic price changes, particularly if these price changes occur in the absence of equally dramatic news.

\section{Behavioral stories}

It is often argued informally that stock-market crashes should be thought of as evidence against traditional, fully-rational models of asset pricing. For example, Shleifer and Summers (1990, p. 19) write: "the stock in the efficient markets hypothesis...crashed along with the rest of the market on October 19, 1987". While this sentiment may well be on target, it strikes us as somewhat ironic that the behavioral finance literature has not really made

\footnotetext{
${ }^{24}$ The same can be said of the "leverage effects" analyzed by Black (1976), Christie (1982) and Schwert (1989): they can clearly create asymmetries, but they cannot deliver price changes that are out of proportion to contemporaneous public news.

${ }^{25}$ A related point, due to Poterba and Summers (1986), is that the quantitative significance of the volatility-feedback effect is likely to be small, since shocks to market volatility are not very persistent.
} 
much progress in understanding crashes; indeed, in our view, not nearly as much as the above-discussed line of work on incomplete information aggregation.

A standard behavioral interpretation of a market crash is that it represents a sudden, radical shift in investor sentiment; in the words of Shiller $(1989$, p. 1) a crash is a time when "the investing public en masse capriciously changes its mind." But, as with the more rational theories, this explanation again leaves unanswered the question of asymmetries: why is it that the biggest capricious changes in sentiment are negative, rather than positive changes? Perhaps one might argue that fear and panic are more powerful emotions than optimism and euphoria, but this strikes us as an unsatisfying rationalization. ${ }^{26}$

In contrast, one of the key selling points of our theory is that one can start with a symmetric driving process for investors' beliefs and still-with the help of the short-sales constraint-generate asymmetries in returns. Certainly one can, in the spirit of Shiller, think of the signals in our model as containing an element of capricious investor sentiment. But now we can say that even if investor $A$ is as likely to become over-optimistic as overpessimistic at time 2 , the market is more likely to melt down than to melt up at this time.

\section{Conclusions}

Throughout the paper, we have attempted to argue that our model does a parsimonious job of fitting a range of existing empirical facts about asymmetries in return distributions, large price movements, etc. But of course, any theory is more attractive if it also offers some novel, as-yet-untested predictions, and thereby puts itself at risk of being rejected in the data.

We believe that Proposition 5-which says that high trading volume should forecast more negative skewness-may be particularly useful in this regard. Indeed, in work that was initiated after the first draft of this paper was completed, (Chen, Hong and Stein (1999)) we conduct a series of cross-sectional tests that are motivated by Proposition 5. We begin by

\footnotetext{
${ }^{26}$ As an alternative to investor-sentiment stories, there are also rational bubble models of the sort described by Blanchard and Watson (1982). The popping of a stochastic bubble can be interpreted as a market crash, and it satisfies our criteria in terms of being both a big move in the absence of news, as well as an inherently asymmetric phenomenon. However, bubble models have not fared well empirically (West (1988), Flood and Hodrick (1990)). Moreover, they have the unattractive feature that the crash, when it occurs, is based on the realization of an extrinsic "sunspot", and hence cannot be explained within the context of the model.
} 
constructing for individual firms a measure of the realized skewness of their daily returns, using six months of data at a time. We then try to forecast this skewness variable, using only prior information. For example, we would try to forecast the realized daily skewness for a given firm over the period January 1 1999-June 30 1999, using information about that firm available prior to January 1 . One of the variables that we use to do this forecast is the firm's detrended turnover from the previous six months (July 1 1998-December 311998 in this example). As it turns out, when turnover is high relative to trend, our estimates suggest that subsequent skewness is in fact more negative. Moreover, across a variety of specifications, the coefficients on turnover are strongly statistically significant, as well as economically meaningful. ${ }^{27}$

While these empirical results are consistent with our theory, we certainly do not mean to suggest at this early stage that there are no alternative explanations. Turnover may well proxy for other things besides differences of opinion-e.g., trading costs-so the data may reflect forces not captured in our model. Rather, the point to be made is simply that the theory has distinctive empirical content, and that the first bits of evidence are encouraging. Clearly there is scope for more empirical work in this vein.

\footnotetext{
${ }^{27}$ A recent paper by Dennis and Mayhew (1999), though it has a quite different motivation, also produces evidence that bears on our hypothesis. Dennis and Mayhew develop, for individual stocks, a measure of implied skewness based on options prices. They then regress this implied skewness measure against a variety of firm-level characteristics. One finding is that, controlling for size, options-implied negative skewness is more pronounced for high-trading-volume firms.
} 


\section{Appendix}

\section{A Proofs of Lemmas}

Proof of Lemma 1. Since $S_{B}$ is uniform on $[0,2 V]$, the risk-neutral arbitrageurs' forecast of $S_{B}$ given that investor $B$ has not submitted an order at trial price $p_{1}$ is given by

$$
\mathrm{E}\left[S_{B} \mid S_{B} \leq p_{1}\right]=p_{1} / 2
$$

hence the risk neutral arbitrageurs' estimate of the terminal value of the asset is

$$
\mathrm{E}\left[D \mid S_{B} \leq p_{1}\right]=(V+H) / 2+p_{1} / 4
$$

For any $p_{1}>S_{B}^{*}$, it is easy to show that $\mathrm{E}\left[D \mid S_{B} \leq p_{1}\right]-p_{1}<0$ and so the auctioneer lowers $p_{1}$ as long as investor $B$ does not submit an order. But since $S_{B}>S_{B}^{*}$, then it follows that $S_{B}$ will be revealed for a low enough $p_{1}$. Hence,

$$
P_{1}=(V+H) / 2+S_{B} / 2
$$

will be the equilibrium price.

Proof of Lemma 2. Suppose $S_{B} \leq S_{B}^{*}$. Then for all trial prices $p_{1}$ where $p_{1} \geq S_{B}^{*}$, it

follows that $S_{B}-p_{1} \leq 0$ and investor $B$ never reveals his information. At $p_{1}=S_{B}^{*}$, the arbitrageurs' expectation of the stock's terminal value,

$$
\mathrm{E}\left[D \mid p_{1}=S_{B}^{*}\right]=(V+H) / 2+S_{B}^{*} / 4,
$$

equals the prevailing trial price and so the market clears at

$$
P_{1}=(V+H) / 2+S_{B}^{*} / 4=2(V+H) / 3
$$

before investor $B$ ever gets into the market. The ex ante probability of winding up in the pooling equilibrium is just

$$
S_{B}^{*} /(2 V)=(V+H) /(3 V),
$$

the probability that $S_{B} \leq S_{B} *$. 
Proof of Lemma 3. Since $S_{A}$ is uniform on $[H, 2 V+H]$, the risk-neutral arbitrageurs' forecast of $S_{A}$ given that investor $A$ has not submitted an order at trial price $p_{2}$ is

$$
\mathrm{E}\left[S_{A} \mid S_{A} \leq p_{2}\right]=\left(H+p_{2}\right) / 2 ;
$$

hence the risk neutral arbitrageurs' estimate of the terminal value of the asset is

$$
\mathrm{E}\left[D \mid S_{A} \leq p_{2}\right]=\left(H+p_{2}\right) / 4+S_{B} / 2 .
$$

For any $p_{2}>S_{A}^{*}$, it is easy to show that $\mathrm{E}\left[D \mid S_{A} \leq p_{2}\right]-p_{2}<0$ and so the auctioneer lowers $p_{2}$ as long as investor $A$ does not submit an order. But since $S_{A}>S_{A}^{*}$, then it follows that $S_{A}$ will be revealed for a low enough $p_{2}$. Hence,

$$
P_{2}=S_{A} / 2+S_{B} / 2
$$

will be the equilibrium price.

Proof of Lemma 4. Suppose $S_{A} \leq S_{A}^{*}$. Then for all trial prices $p_{2}$ where $p_{2} \geq S_{A}^{*}$, it follows that $S_{A}-p_{2} \leq 0$ and investor $A$ never reveals his information. At $p_{2}=S_{A}^{*}$, the arbitrageurs' expectation of the stock's terminal value,

$$
\mathrm{E}\left[D \mid p_{2}=S_{A}^{*}\right]=\left(H+S_{A}^{*}\right) / 4+S_{B} / 2,
$$

equals the prevailing trial price and so the market clears at

$$
P_{2}=\left(H+S_{A}^{*}\right) / 4+S_{B} / 2=\left(2 S_{B}+H\right) / 3
$$

before investor $A$ ever gets into the market.

Proof of Lemma 5. We know that no new information regarding investor $B$ 's valuation arrives at $t=2$ and (from Lemma 2) $S_{B}$ was hidden at equilibrium price

$$
P_{1}=(V+H) / 2+S_{B}^{*} / 4 .
$$

If $S_{A}>(V+H)$, then it follows that $S_{A}-p_{2}>0$ for some $p_{2}>P_{1}$ and hence $S_{A}$ will be revealed for some $p_{2}>P_{1}$. So,

$$
P_{2}=S_{A} / 2+S_{B}^{*} / 4=S_{A} / 2+(V+H) / 6
$$


will be the equilibrium price, and the market clears before any new information on $S_{B}$ can be revealed.

Proof of Lemma 6. Since $S_{B} \leq S_{B}^{* *}$, where $S_{B}^{* *}=2 S_{A} / 3$, it follows that $S_{A}$ will be revealed before $S_{B}$ during the auction. Given that $S_{A}$ has been revealed, the risk neutral arbitrageurs' estimate of the terminal value of the asset at trial price $p_{2}$ is

$$
\mathrm{E}\left[D \mid S_{B} \leq p_{2}\right]=S_{A} / 2+p_{2} / 4
$$

Since $S_{B} \leq S_{B}^{* *}$, then for all trial prices $p_{2}$ where $p_{2} \geq S_{B}^{* *}$, it follows that $S_{B}-p_{2} \leq 0$ and investor $B$ never reveals his information. At $p_{2}=S_{B}^{* *}$, the arbitrageurs' expectation of the stock's terminal value,

$$
\mathrm{E}\left[D \mid p_{2}=S_{B}^{* *}\right]=S_{A} / 2+S_{B}^{* *} / 4
$$

equals the prevailing trial price and so the market clears at

$$
P_{2}=S_{A} / 2+S_{B}^{* *} / 4=2 S_{A} / 3
$$

before investor $B$ ever gets into the market.

Proof of Lemma 7. It is easy to verify that if $S_{A} \leq S_{A}^{*}$ and $S_{B}>H$ (given that $S_{B}<S_{B}^{*}$ ), then $S_{A}<S_{B}$. Hence, $S_{B}$ will be revealed before $S_{A}$. Given that $S_{B}$ has been revealed, the risk neutral arbitrageurs' estimate of the terminal value of the asset at trial price $p_{2}$ is

$$
\mathrm{E}\left[D \mid S_{A}<p_{2}\right]=\left(H+p_{2}\right) / 4+S_{B} / 2 .
$$

Since $S_{A} \leq S_{A}^{*}$, then for all trial prices $p_{2}$ where $p_{2} \geq S_{A}^{*}$, it follows that $S_{A}-p_{2} \leq 0$ and investor $A$ never reveals his information. At $p_{2}=S_{A}^{*}$, the arbitrageurs' expectation of the stock's terminal value,

$$
\mathrm{E}\left[D \mid p_{2}=S_{A}^{*}\right]=\left(H+S_{A}^{*}\right) / 4+S_{B} / 2
$$

equals the prevailing trial price and so the market clears at

$$
P_{2}=\left(H+S_{A}^{*}\right) / 4+S_{B} / 2=\left(2 S_{B}+H\right) / 3
$$

before investor $A$ ever gets into the market.

Proof of Lemma 8. It is easy to verify from Figure 1 that the only parameter region that remains is the case where $2(V+H) / 3>S_{B}>2 H / 3$ and for a fixed realization of 
$S_{B}, S_{A} \in\left(\left(2 S_{B}+H\right) / 3,3 S_{B} / 2\right)$. In this parameter region, $S_{A}$ and $S_{B}$ are not too far apart and $S_{B}$ is not too small, so both values are revealed in the auction process. More precisely, the conditions required for either one to remain hidden - as established in the previous lemmas - cannot be established. So,

$$
P_{2}=S_{A} / 2+S_{B} / 2
$$

is the equilibrium price.

Proof of Lemma 9. Let $P_{0}=V+H / 2$. Then

$$
\mathrm{E}\left[R_{1}^{3}\right]=\mathrm{E}\left[R_{1}^{3} \mid S_{B}>S_{B}^{*}\right] \operatorname{prob}\left(S_{B}>S_{B}^{*}\right)+\mathrm{E}\left[R_{1}^{3} \mid S_{B} \leq S_{B}^{*}\right] \operatorname{prob}\left(S_{B} \leq S_{B}^{*}\right) .
$$

Then from the fact that $S_{B}$ is uniform on $[0,2 V]$,

$$
\mathrm{E}\left[R_{1}^{3}\right]=\frac{1}{2 V}\left[\int_{S_{B}^{*}}^{2 V}\left(\frac{V+H+y}{2}-P_{0}\right)^{3} d y+\int_{0}^{S_{B}^{*}}\left(S_{B}^{*}-P_{0}\right)^{3} d y\right] .
$$

It can be shown that

$$
\mathrm{E}\left[R_{1}^{3}\right]=-\frac{(H-2 V)(H+V)^{3}}{648 V} .
$$

Since $H \leq 2 V$, it follows that $\forall H$ and $V, E\left[R_{1}^{3}\right] \geq 0$.

Proof of Lemma 10. First, we calculate $\mathrm{E}\left[R_{2}^{3}\right]$ conditional on being in Case I, in which $S_{B}$ is revealed at $t=1$, i.e. $S_{B}>S_{B}^{*}$. For convenience, let $x=S_{A}$ and $y=S_{B}$. Under Case I, the price is simply $P_{1}=(V+H) / 2+y / 2$. Then

$$
\begin{aligned}
\mathrm{E}\left[R_{2}^{3} \mid \text { Case } \mathrm{I}\right] & =\frac{1}{\left(2 V-S_{B}^{*}\right)} \frac{1}{2 V} \int_{S_{B}^{*}}^{2 V}\left[\int_{H}^{\frac{2 y+H}{3}}\left(\frac{2 y+H}{3}-P_{1}\right)^{3} d x\right. \\
& \left.+\int_{\frac{2 y+H}{3}}^{2 V+H}\left(\frac{x+y}{2}-P_{1}\right)^{3} d x\right] d y .
\end{aligned}
$$

Since $S_{A}$ and $S_{B}$ are independent and uniformly distributed, we have that

$$
\mathrm{E}\left[R_{2}^{3} \mid \text { Case } \mathrm{I}\right]=-\frac{(H-2 V)^{3}(121 H+208 V)}{262440 V} .
$$

Here, since $H \leq 2 V$, it follows that $\mathrm{E}\left[R_{2}^{3} \mid\right.$ CaseI $] \geq 0$.

Now, we calculate $\mathrm{E}\left[R_{2}^{3}\right]$ conditional on being in Case II, in which $S_{B}$ is hidden at $t=1$, i.e. $S_{B} \leq S_{B}^{*}$. Under Case II, the price is simply $P_{1}=S_{B}^{*}$. We will calculate

$$
\mathrm{E}\left[R_{2}^{3} \mid \text { Case II }\right]=\frac{1}{S_{B}^{*}} \frac{1}{2 V} \sum_{i=1}^{3} E^{i}
$$


where $E^{1}$ is given by

$$
E^{1}=\int_{0}^{2 H / 3}\left[\int_{H}^{V+H}\left(\frac{x}{2}+\frac{2 x / 3}{4}-P_{1}\right)^{3} d x+\int_{V+H}^{2 V+H}\left(\frac{x}{2}+\frac{V+H}{6}-P_{1}\right)^{3} d x\right] d y
$$

$E^{2}$ is given by

$$
\begin{aligned}
E^{2} & =\int_{2 H / 3}^{H}\left[\int_{H}^{\frac{3 y}{2}}\left(\frac{x+y}{2}-P_{1}\right)^{3} d x+\int_{\frac{3 y}{2}}^{V+H}\left(\frac{x}{2}+\frac{2 x / 3}{4}-P_{1}\right)^{3} d x\right. \\
& \left.+\int_{V+H}^{2 V+H}\left(\frac{x}{2}+\frac{V+H}{6}-P_{1}\right)^{3} d x\right] d y
\end{aligned}
$$

and $E^{3}$ is given by

$$
\begin{aligned}
E^{3} & =\int_{H}^{S_{B}^{*}}\left[\int_{H}^{\frac{2 y+H}{3}}\left(\frac{2 y+H}{3}-P_{1}\right)^{3} d x+\int_{\frac{2 y+H}{3}}^{\frac{3 y}{2}}\left(\frac{x+y}{2}-P_{1}\right)^{3} d x\right. \\
& \left.+\int_{\frac{3 y}{2}}^{V+H}\left(\frac{x}{2}+\frac{2 x / 3}{4}-P_{1}\right)^{3} d x+\int_{V+H}^{2 V+H}\left(\frac{x}{2}+\frac{V+H}{6}-P_{1}\right)^{3} d x\right] d y .
\end{aligned}
$$

Since $S_{A}$ and $S_{B}$ are independent and uniformly distributed, we have that

$$
\mathrm{E}\left[R_{2}^{3} \mid \text { Case II }\right]=-\frac{7 H^{5}-70 H^{4} V-935 H^{3} V^{2}+5515 H^{2} V^{3}+9065 H V^{4}+2935 V^{5}}{1049760 V(H+V)} .
$$

Without loss of generality, let $H=\alpha V$, where $\alpha \in[0,2]$, i.e. $\alpha=H / V$. Let

$$
f(\alpha)=\frac{\mathrm{E}\left[R_{2}^{3} \mid \text { Case II }\right]}{V^{3}} .
$$

Note that $f(0)=-587 / 209952$ and $f(2)=-143 / 1296$, where $f(0)<f(2)$. Furthermore,

$$
f^{\prime}(\alpha)=-\frac{6130+11030 \alpha+2710 \alpha^{2}-2150 \alpha^{3}-175 \alpha^{4}+28 \alpha^{5}}{1049760(1+\alpha)^{2}} .
$$

It is easy to show that $\forall \alpha, f^{\prime}(\alpha)<0$. Note also that $\max f^{\prime}(\alpha)=-41 / 19440$ and $\operatorname{argmax} f^{\prime}(\alpha)=2$. Hence, $\forall H \in[0,2 V], \mathrm{E}\left[R_{2}^{3} \mid\right.$ Case II $]<0$; moreover, $\mathrm{E}\left[R_{2}^{3} \mid\right.$ Case II $]$ decreases monotonically with $H / V$.

Since the probability of being in Case I is $\left(2 V-S_{B}^{*}\right) / 2 V$ and the probability of being in Case II is $S_{B}^{*} / 2 V$, it follows that

$$
\mathrm{E}\left[R_{2}^{3}\right]=\mathrm{E}\left[R_{2}^{3} \mid \text { Case } \mathrm{I}\right] \frac{\left(2 V-S_{B}^{*}\right)}{2 V}+\mathrm{E}\left[R_{2}^{3} \mid \text { Case II }\right] \frac{S_{B}^{*}}{2 V}
$$


Simplifying, we have

$$
\mathrm{E}\left[R_{2}^{3}\right]=\frac{53 H^{5}-330 H^{4} V+655 H^{3} V^{2}-115 H^{2} V^{2}-3105 H V^{4}+1153 V^{5}}{349920 V^{2}} .
$$

Let

$$
g(\alpha)=\mathrm{E}\left[R_{2}^{3}\right] / V^{3} .
$$

Note that $g(0)=1153 / 349920$ and $g(2)=-143 / 12960$. Furthermore,

$$
g^{\prime}(\alpha)=\frac{-3105-230 \alpha+1965 \alpha^{2}-1320 \alpha^{3}+265 \alpha^{4}}{349920} .
$$

It is easy to show that $\forall \alpha, g^{\prime}(\alpha)<0$ since $\max g^{\prime}(\alpha)=-5 / 864$ and $\operatorname{argmax} g^{\prime}(\alpha)=2$. Moreover, $\mathrm{E}\left[R_{2}^{3}\right]=0$ for $H / V \approx .3756$. Hence, $\mathrm{E}\left[R_{2}^{3}\right]$ monotonically decreases with $H / V$ and is negative for $H / V>.3756$.

\section{B Proofs of Propositions}

Proof of Proposition 1. Since $S_{B}$ and $S_{A}$ are symmetrically distributed (with the same variance) and are fully revealed at time 1 and 2 respectively, the fact that prices are efficient means that returns are symmetrically distributed and homoskedastic.

Proof of Proposition 2. This follows easily from the calculations provided in Section III.C.1 of the text.

Proof of Proposition 3. From (A.23) and (A.34), we have that

$$
\mathrm{E}\left[R_{s}^{3}\right]=\frac{2233 V^{5}-405 H V^{4}+1505 H^{2} V^{3}+115 H^{3} V^{2}-870 H^{4} V+53 H^{5}}{699840 V^{2}} .
$$

Then let

$$
h(\alpha)=\frac{\mathrm{E}\left[R_{s}^{3}\right]}{V^{3}} .
$$

Note that $h(0)=223 / 699840, h(2)=-143 / 25920$ and $h(1.691)=0$. Using similar arguments to those in Lemma 10, it is not hard to show that for $H / V>1.691, \mathrm{E}\left[R_{s}^{3}\right]<0$.

Proof of Proposition 4. We now calculate the medium-horizon skewness $E\left[R_{m}^{3}\right]$. Using the same arguments as in Lemmas 9 and 10, we have

$$
\mathrm{E}\left[R_{m}^{3}\right]=\frac{-8 V^{5}+145 H V^{4}-30 H^{2} V^{3}+40 H^{3} V^{2}-50 H^{4} V+H^{5}}{51840 \sqrt{2}} .
$$


From (A.37) and (A.39), we can define the difference between the short-horizon and the medium-horizon skewness as

$$
\Delta=\frac{\mathrm{E}\left[R_{s}^{3}\right]-\mathrm{E}\left[R_{m}^{3}\right]}{V^{3}} .
$$

It is not hard to show that $\forall \alpha>1.834, \Delta<0$. So for sufficiently large values of $H / V$, there is less negative skewness in medium-horizon returns than in short-horizon returns.

Proof of Proposition 6. We will present the proof for $\hat{\rho}_{i j}$; the proof for $\hat{\sigma}_{i j}$ is a simpler variation on the same argument. Recall our definition of $\hat{\rho}_{i j}$ :

$$
\hat{\rho}_{i j}=\frac{\mathrm{E}\left[R_{i} R_{j} \mid R_{M}\right]}{\sqrt{\mathrm{E}\left[R_{i}^{2} \mid R_{M}\right] \mathrm{E}\left[R_{j}^{2} \mid R_{M}\right]}} .
$$

Since $R_{i}=R_{M}+Z_{i}$, it follows that

$$
\hat{\rho}_{i j}=\frac{R_{M}^{2}}{R_{M}^{2}+\sigma_{Z}^{2}} .
$$

where $\sigma_{Z}^{2}$ is the variance of the $Z_{i}$ 's. Then observe that

$$
\frac{1}{\hat{\rho}_{i j}-1}=-\frac{R_{M}^{2}}{\sigma_{Z}^{2}}-1 \text {. }
$$

So, we have

$$
\mathrm{E}\left[\frac{1}{\hat{\rho}_{i j}-1} R_{M}\right]=\mathrm{E}\left[-\frac{R_{M}^{3}}{\sigma_{Z}^{2}}-R_{M}\right]=-\frac{\mathrm{E}\left[R_{M}^{3}\right]}{\sigma_{Z}^{2}}>0,
$$

since $\mathrm{E}\left[R_{M}^{3}\right]<0$ by assumption. It follows then that

$$
\mathrm{E}\left[\hat{\rho}_{i j} R_{M}\right]<0,
$$

since

$$
\frac{\partial}{\partial \hat{\rho}_{i j}}\left(\frac{1}{\hat{\rho}_{i j}-1}\right)<0
$$

Proof of Proposition 7. We first define some simplifying notations. Let

$$
\hat{S}_{B, k}=\mathrm{E}_{2+}\left[S_{B, k}\right]
$$

be the conditional expectation of $S_{B, k}$ at time $t=2+$ for $k=i, j$. Then define the operator $\delta$, applied to a random variable $X$, as

$$
\delta X=X-\mathrm{E}_{0}[X]
$$


We can then rewrite

$$
\begin{aligned}
R_{i} & =\frac{1}{2}\left(\delta S_{A, i}+\delta \hat{S}_{B, i}+\gamma \delta \hat{S}_{B, j}\right), \\
R_{j} & =\frac{1}{2}\left(\delta S_{A, j}+\gamma \delta \hat{S}_{B, i}+\delta \hat{S}_{B, j}\right), \\
R_{M} & =\frac{1}{4}\left(\delta\left(S_{A, i}+S_{A, j}\right)+(1+\gamma)\left(\delta \hat{S}_{B, i}+\delta \hat{S}_{B, j}\right)\right) .
\end{aligned}
$$

Using the expressions for $R_{i}, R_{j}$ and $R_{M}$ given in (A.49), we can expand $\mathrm{E}\left[R_{i} R_{j} R_{M}\right]$ as a polynomial function of $\delta S_{A, k}$ and $\delta \hat{S}_{B, k}$ for $k=i, j$. All terms of this polynomial will be zero except for $\mathrm{E}\left[\delta S_{A, k}\left(\delta \hat{S}_{B, k}\right)^{2}\right]<0$ for $k=i, j$. (These terms are negative based on the logic from our one-asset version of the model.) It follows that

$$
\mathrm{E}\left[R_{i} R_{j} R_{M}\right]=\frac{1}{16} \mathrm{E}\left[\gamma(2+\gamma) \delta S_{A, i}\left(\delta \hat{S}_{B, i}\right)^{2}+\gamma(2+\gamma) \delta S_{A, j}\left(\delta \hat{S}_{B, j}\right)^{2}\right]<0
$$




\section{References}

Bakshi, Gurdip, Cao, Charles and Chen, Zhiwu, 1997, "Empirical Performance of Alternative Option Pricing Models," Journal of Finance 52, 2003-49.

Bates, David, 1997, "Post-'87 Crash Fears in S\&P 500 Futures Options," NBER Working Paper Series.

Bekaert, Geert and Wu, Goujun, "Asymmetric Volatility and Risk in Equity Markets," Stanford Business School Working Paper.

Black, Fischer, 1976, "Studies of Stock price Volatility Changes," Proceedings of the 1976 Meetings of the American Statistical Association, Business and Economical Statistics Section, 177-81.

Blanchard, Olivier J. and Watson, Mark W., 1982, "Bubbles, Rational Expectations, and Financial Markets," in Paul Wachtel, ed. Crises in Economic and Financial Structure. (Lexington MA: Lexington Books) pp. 295-315.

Braun, Phillip A., Nelson, Daniel B. and Sunier, Alain M., 1995 "Good News, Bad News, Volatility, and Betas," Journal of Finance, 50, 1575-1603.

Campbell, John Y. and Hentschel, Ludger, 1992, "No News Is Good News: An Asymmetric Model of Changing Volatility in Stock Returns," Journal of Financial Economics, 31, 281-318.

Chen, Joseph, Hong, Harrison, and Stein, Jeremy C., 1999, "Forecasting Crashes: Trading Volume, Past Returns, and Conditional Skewness in Stock Prices," draft in progress.

Christie, Andrew A., 1982, "The Stochastic Behavior of Common Stock Variances - Value, Leverage and Interest Rate Effects," Journal of Financial Economics, 10, 407-432.

Coval, Joshua D. and Hirshleifer, David, 1998, "Trading-Generated News, Sidelined Investors, and Conditional Patterns in Security returns," University of Michigan Business School Working Paper. 
Cutler, David M., Poterba, James M. and Summers, Lawrence H., 1989, "What Moves Stock Prices?" Journal of Portfolio Management, 15, 4-12.

DeLong, J. Bradford, Shleifer, Andrei, Summers, Lawrence H and Waldmann, Robert J, 1990, "Noise Trader Risk in Financial Markets," Journal of Political Economy, 98, 703-38.

Dennis, Patrick and Mayhew, Stewart, 1999, "Implied Volatility Smiles: Evidence from Options on Individual Equities," Purdue University Working Paper.

Derman, Emanuel, 1999, "Regimes of Volatility: Some Observations on the Variation of S\&P 500 Implied Volatilities," Goldman Sachs Quantitative Strategies Research Notes.

Diamond, Douglas W. and Verrechia, Robert E., 1987, "Constraints on Short-Selling and Asset Price Adjustment to Private Information," Journal of Financial Economics, 18, 277-311.

Domowitz, Ian and Madhavan, Ananth, 1998, "Open Sesame: Alternative Open Algorithms in Securities Markets," USC Business School Working Paper.

Duffee, Gregory R., 1995a, "Stock Returns and Volatility: A Firm-Level Analysis," Journal of Financial Economics, 37, 399-420.

Duffee, Gregory R., 1995b, "Asymmetric Cross-sectional Dispersion in Stock Returns: Evidence and Implications," Board of Governors Working Paper.

Dumas, Bernard, Fleming, Jeff and Whaley, Robert E., 1998, "Implied Volatility Functions: Empirical Tests," Journal of Finance, 53, 2059-2106.

Engle, Robert F. and Ng, Victor K., 1993, "Measuring and Testing the Impact of News on Volatility," Journal of Finance, 48, 1749-78.

Flood, Robert P. and Hodrick, Robert J., 1990, "On Testing for Speculative Bubbles," Journal of Economic Perspectives, 4, 85-101. 
French, Kenneth R. and Roll, Richard, 1986, "Stock Return Variances: The Arrival of Information and the Reaction of Traders," Journal of Financial Economics,17, 5-26.

French, Kenneth R., Schwert, G. William and Stambaugh, Robert F., 1987, "Expected Stock Returns and Volatility," Journal of Financial Economics, 19, 3-29.

Genotte, Gerard and Leland, Hayne, 1990, "Market Liquidity, Hedging and Crashes," American Economic Review, 80, 999-1021.

Glosten, Lawrence, Jagannathan, Ravi and Runkle, David E., 1993, "On the Relation between the Expected Value and the Volatility of the Nominal Excess Return on Stocks," Journal of Finance, 48, 1779-1801.

Greenwald, Bruce C. and Stein, Jeremy C., 1991, "Transactional Risk, Market Crashes, and the Role of Circuit Breakers," Journal of Business, 64, 443-462.

Grossman, Sanford J., 1988, "An Analysis of the Implications for Stock and Futures Price Volatility of Program Trading and Dynamic Hedging Strategies," Journal of Business, $61,275-98$.

Harris, Milton and Raviv, Artur, 1993, "Differences of Opinion Make a Horse Race," Review of Financial Studies, 6, 473-506.

Harrison, J. Michael and Kreps, David M., 1978, "Speculative Investor Behavior in a Stock Market with Heterogeneous Expectations," Quarterly Journal of Economics, 93, 323336.

Hong, Harrison and Stein, Jeremy C., 1999, "A Unified Theory of Underreaction, Momentum Trading, and Overreaction in Asset Markets," forthcoming in Journal of Finance.

Jacklin, Charles J., Kleidon, Allan W. and Pfleiderer, Paul, 1992, "Underestimation of Portfolio Insurance and the Crash of October 1987," Review of Financial Studies, 5, 35-63.

Kandel, Eugene and Pearson, Neil D., 1995, "Differential Interpretation of Public Signals and Trade in Speculative Markets," Journal of Political Economy, 103, 831-72. 
Kelly, Michael, 1994, "Correlation: Stock Answer," Risk, v7, n8, 40-43.

Kleidon, Allan W., 1994, "Stock Market Crashes," Stanford Business School Research Paper.

Kodres, Laura E. and Pritsker, Matthew, 1998, "A Rational Expectations Model of Financial Contagion," working paper.

Koski, Jennifer Lynch and Pontiff, Jeffrey, 1999, "How Are Derivatives Used? Evidence from the Mutual Fund Industry," Journal of Finance, 54, 791-816.

Nelson, Daniel, 1991, "Conditional Heteroskedasticity in Asset Returns: A New Approach," Econometrica, 59, 347-370.

Odean, Terrance, 1998, "Volume, Volatility, Price and Profit When all Traders Are Above Average," Journal of Finance, 53, 1887-1934.

Pindyck, Robert S., 1984, "Risk, Inflation, and the Stock Market," American Economic Review, 74, 334-351.

Poterba, James M. and Summers, Lawrence H., 1986, "The Persistence of Volatility and Stock Market Fluctuations," American Economic Review, 76, 1142-1151.

Presidential Task Force on Market Mechanism (Brady Commission), 1988, Report, U.S. Government Printing Office, Washington, D.C.

Roll, Richard, 1984, "Orange Juice and Weather," American Economic Review, 74, 861880.

Roll, Richard, 1988, " $R^{2}$," Journal of Finance, 43, 541-66.

Romer, David, 1993, "Rational Asset-Price Movements without News," American Economic Review, 83, 1112-30.

Schwert, G. William, 1989, "Why Does Stock Market Volatility Change over Time?," Journal of Finance, 44, 1115-1153. 
Shleifer, Andrei and Summers, Lawrence H., 1990, "The Noise Trader Approach to Finance," Journal of Economic Perspectives, 4, 19-33.

Shiller, Robert J., 1989, Market Volatility, (MIT Press, Cambridge, Mass. and London).

Varian, H.R., 1989, "Differences of Opinion in Financial Markets," in Financial Risk: Theory, Evidence and Implications: Proceedings of the 11-th Annual Economic Policy Conference of the Federal Reserve Bank of St. Louis, ed. by C.C. Stone. Boston: Kluwer Academic Publishers, 3-37.

West, Kenneth D., 1988, "Bubbles, Fads and Stock Price Volatility Tests: A Partial Evaluation," Journal of Finance, 43, 639-656.

Wu, Guojun, 1997, "The Determinants of Asymmetric Volatility," Stanford Business School Working Paper. 
Figure 1: Partition of Equilibrium Outcomes Depending on A's and B's Signals, $S_{A}$ and $S_{B}$ respectively. Graphical classification of Cases I.A, I.B, II.A, II.B, II.C and II.D characterized in Lemmas 3-8.

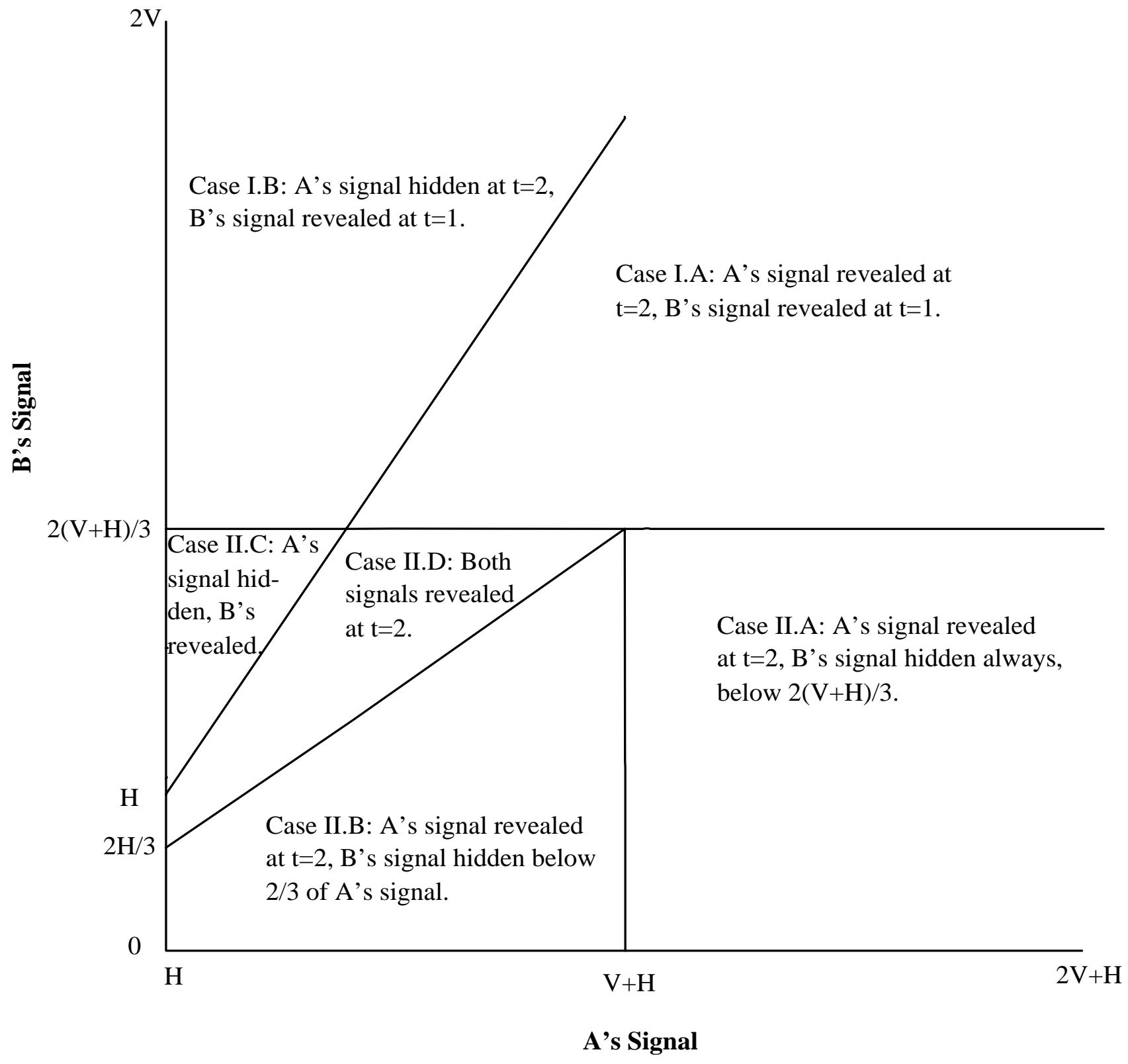


Figure 2: Skewness and Differences of Opinion. Plot of various skewness measures against a measure of differences of opinion, $H / V$.

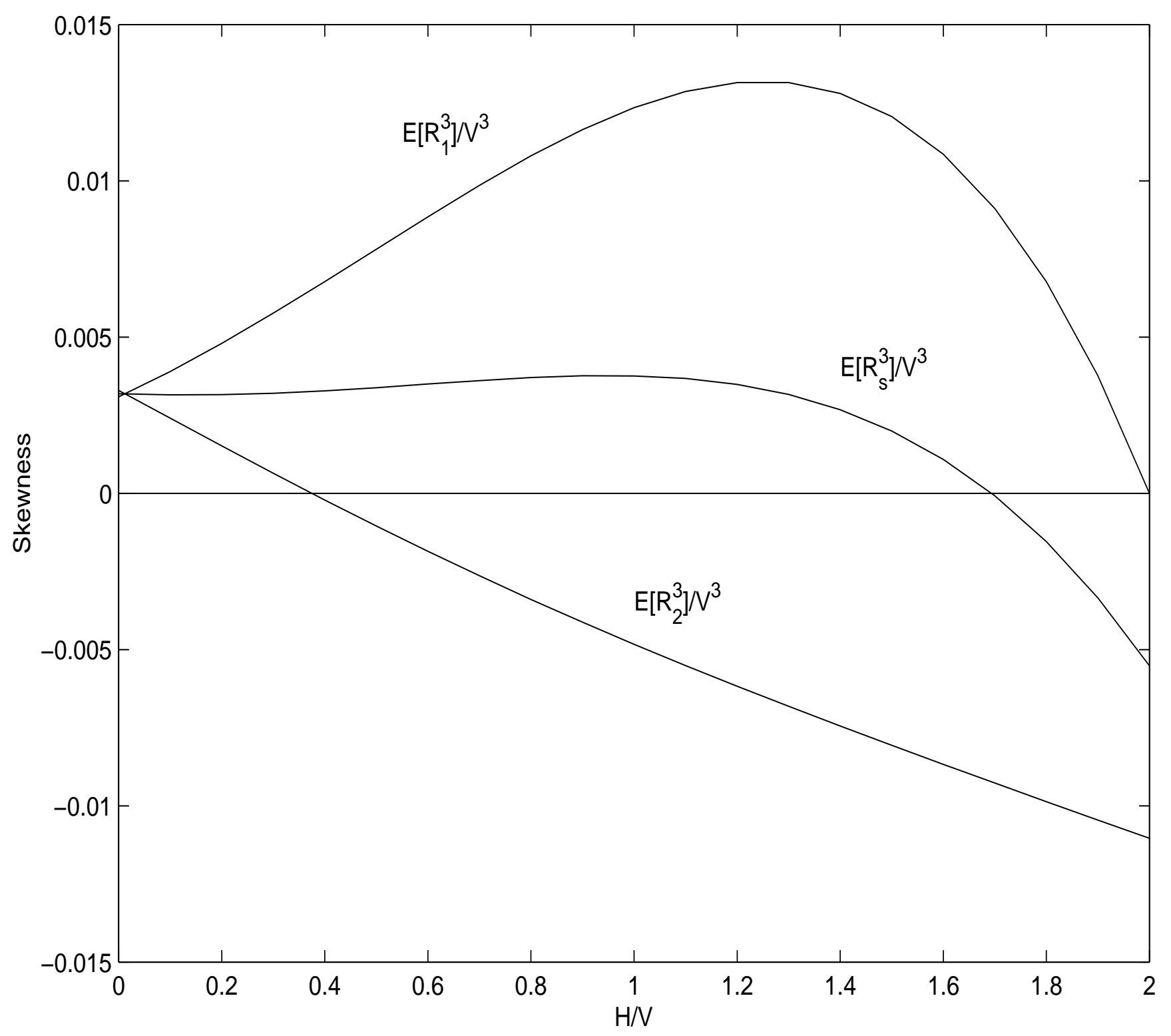


To order any of these papers in hard copy, see instructions at the end of this list. To subscribe to all NBER Working Papers or the papers in a single area, see instructions inside the back cover.

Number

7373

7330
Author(s)

Harry Holzer

David Neumark

Mark McClellan

Douglas Staiger

David Ikenberry

Josef Lakonishok

Theo Vermaelen

Thomas C. Kinnaman

Don Fullerton

Mark McClellan

Douglas Staiger

John DiNardo

Mark P. Moore

Austan Goolsbee

Peter J. Klenow

Young-Hye Cho

Robert F. Engle

Young-Hye Cho

Robert F. Engle

Daniel S. Hamermesh

James L. Heckman

Rajesh K. Aggarwal

Andrew A. Samwick

Rajesh K. Aggarwal Andrew A. Samwick

Richard Portes

Hélène Rey $\underline{\text { Title }}$

Date

Assessing Affirmative Action

Comparing Hospital Quality at For-Profit and Not-for- $\quad 8 / 99$ Profit Hospitals

Stock Repurchases in Canada: Performance and Strategic 8/99 Trading

The Economics of Residential Solid Waste Management

$8 / 99$

The Quality of Health Care Providers

$8 / 99$

The Phillips Curve is Back? Using Panel Data to $8 / 99$ Analyze the Relationship Between Unemployment and Inflation in an Open Economy

Evidence on Learning and Network Externalities in the $9 / 99$ Diffusion of Home Computers

Time-Varying Betas and Asymmetric Effect of News: $\quad 9 / 99$ Empirical Analysis of Blue Chip Stocks

Modeling the Impacts of Market Activity on Bid-Ask $\quad 9 / 99$ Spreads in the Option Market

The Changing Distribution of Job Satisfaction $9 / 99$

Causal Parameters and Policy Analysis in Economics: $9 / 99$ A Twentieth Century Retrospective

Performance Incentives Within Firms: The Effect of $9 / 99$ Managerial Responsibility

Empire-Builders and Shirkers: Investment, Firm 9/99 Performance, and Managerial Incentives

The Determinants of Cross-Border Equity Flows

$9 / 99$

You can download these and other papers at the NBER Web site: 
To order any of these papers in hard copy, see instructions at the end of this list. To subscribe to all NBER Working Papers or the papers in a single area, see instructions inside the back cover.

Number

7337

7338

7339

7340

7344

7345

7346
Author(s)

Kathryn M. Dominguez

Jeffrey A. Frankel

Axel Börsch-Supan

Hylke Vandenbussche

Jozef Konings

Linda Springael

Robert F. Engle

Simone Manganelli

David C. King

Richard J. Zeckhauser

Christina Paxson

Jane Waldfogel

Michael Hout

Harvey S. Rosen

Jean O. Lanjouw

Mark Schankerman

Geert Bekaert

Steven R. Grenadier

Thomas N. Hubbard

Jonathan Gruber

Edward P. Lazear

Tamim Bayoumi

Taizo Motonishi

Hiroshi Yoshikawa
Title

Date

The Market Microstructure of Central Bank Intervention 9/99

No Single Currency Regime is Right for all Countries $\quad 9 / 99$ or at All Times

Incentive Effects of Social Security Under an Uncertain $\quad 9 / 99$ Disability Option

Import Diversion under European Antidumping Policy $\quad 9 / 99$

CAViaR: Conditional Value at Risk By Quantile

$9 / 99$

Regression

Congressional Vote Options

Work, Welfare, and Child Maltreatment

$9 / 99$

Self-Employment, Family Background, and Race

$9 / 99$

The Quality of Ideas: Measuring Innovation with

$9 / 99$

Multiple Indicators

Stock and Bond Pricing in an Affine Economy

$9 / 99$

How Wide Is the Scope of Hold-Up-Based Theories?

$9 / 99$

Contractual Form and Market Thickness in Trucking

The Wealth of the Unemployed: Adequacy and Implications for Unemployment Insurance

Educational Production

The Morning After: Explaining the Slowdown in Japanese Growth in the 1990 s

Causes of the Long Stagnation of Japan during the

$9 / 99$ 1990's: Financial or Real?

You can download these and other papers at the NBER Web site:

\section{www.nber.org}

Free searchable abstracts are also available at the site. 
To order any of these papers in hard copy, see instructions at the end of this list. To subscribe to all NBER Working Papers or the papers in a single area, see instructions inside the back cover.

\begin{tabular}{|c|c|}
\hline Number & Author(s) \\
\hline 7352 & $\begin{array}{l}\text { Daron Acemoglu } \\
\text { Robert Shimer }\end{array}$ \\
\hline 7353 & $\begin{array}{l}\text { Jeff Grogger } \\
\text { Charles Michalopoulos }\end{array}$ \\
\hline 7354 & Roberto Rigobon \\
\hline 7355 & $\begin{array}{l}\text { Ricardo J. Caballero } \\
\text { Mohamad L. Hammour }\end{array}$ \\
\hline 7356 & $\begin{array}{l}\text { Alec Ian Gershberg } \\
\text { Michael Grossman } \\
\text { Fred Goldman }\end{array}$ \\
\hline 7357 & Robert E. Lipsey \\
\hline 7358 & Vernon Henderson \\
\hline 7359 & $\begin{array}{l}\text { Iain Cockburn } \\
\text { Rebecca Henderson } \\
\text { Scott Stern }\end{array}$ \\
\hline 7360 & $\begin{array}{l}\text { Douglas Holtz-Eakin } \\
\text { John W. Phillips } \\
\text { Harvey S. Rosen }\end{array}$ \\
\hline 7361 & $\begin{array}{l}\text { Bong-Chan Kho } \\
\text { René M. Stulz }\end{array}$ \\
\hline 7362 & $\begin{array}{l}\text { Jagadeesh Gokhale } \\
\text { Laurence J. Kotlikoff }\end{array}$ \\
\hline 7363 & $\begin{array}{l}\text { Bruce D. Meyer } \\
\text { Dan T. Rosenbaum }\end{array}$ \\
\hline 7364 & $\begin{array}{l}\text { Dani Rodrik } \\
\text { Andrés Velasco }\end{array}$ \\
\hline 7365 & $\begin{array}{l}\text { Michael D. Bordo } \\
\text { Lars Jonung }\end{array}$ \\
\hline
\end{tabular}

Title

$\underline{\text { Date }}$

Productivity Gains From Unemployment Insurance $\quad 9 / 99$

Welfare Dynamics under Time Limits

$9 / 99$

On the Measurement of the International Propagation

9/99

of Shocks

The Cost of Recessions Revisited: A Reverse-

$9 / 99$

Liquidationist View

Competition and the Cost of Capital Revisited: Special $\quad$ 9/99

Authorities and Underwriters in the Market for Tax-

exempt Hospital Bonds

Foreign Production by U.S. Firms and Parent Firm

$9 / 99$

Employment

Marshall's Economies

$9 / 99$

The Diffusion of Science-Driven Drug Discovery:

Organizational Change in Pharmaceutical Research

$9 / 99$

Estate Taxes, Life Insurance, and Small Business

Banks, the IMF, and the Asian Crisis

Social Security's Treatment of Postwar Americans:

How Bad Can It Get?

Welfare, the Earned Income Tax Credit, and the

Short-Term Capital Flows

The Future of EMU: What Does the History of Monetary Unions Tell Us?

You can download these and other papers at the NBER Web site:

www.nber.org

Free searchable abstracts are also available at the site. 
To order any of these papers in hard copy, see instructions at the end of this list. To subscribe to all NBER Working Papers or the papers in a single area, see instructions inside the back cover.

\begin{tabular}{|c|c|}
\hline Number & Author(s) \\
\hline 7366 & Emmanuel Saez \\
\hline 7367 & Emmanuel Saez \\
\hline 7368 & $\begin{array}{l}\text { Alan L. Gustman } \\
\text { Thomas L. Steinmeier }\end{array}$ \\
\hline 7369 & $\begin{array}{l}\text { Wolfgang Keller } \\
\text { Arik Levinson }\end{array}$ \\
\hline 7370 & $\begin{array}{l}\text { Michael Baker } \\
\text { Gary Solon }\end{array}$ \\
\hline 7371 & $\begin{array}{l}\text { Michael Baker } \\
\text { Nicole M. Fortin }\end{array}$ \\
\hline 7372 & $\begin{array}{l}\text { B. Douglas Bernheim } \\
\text { Lorenzo Forni } \\
\text { Jagadeesh Gokhale } \\
\text { Laurence J. Kotlikoff }\end{array}$ \\
\hline 7373 & $\begin{array}{l}\text { Paul A. David } \\
\text { Bronwyn H. Hall } \\
\text { Andrew A. Toole }\end{array}$ \\
\hline 7374 & $\begin{array}{l}\text { Peter Cappelli } \\
\text { David Neumark }\end{array}$ \\
\hline 7375 & Charles I. Jones \\
\hline 7376 & $\begin{array}{l}\text { Harrison Hong } \\
\text { Jeremy C. Stein }\end{array}$ \\
\hline
\end{tabular}

Title

$\underline{\text { Date }}$

Do Taxpayers Bunch at Kink Points? $\quad 9 / 99$

The Effect of Marginal Tax Rates on Income: A Panel $\quad 9 / 99$ Study of 'Bracket Creep'

What People Don't Know About Their Pensions $9 / 99$ and Social Security: An Analysis Using Linked Data From The Health and Retirement Study

Environmental Compliance Costs and Foreign Direct Investment Inflows to U.S. States

$9 / 99$

Earnings Dynamics and Inequality among Canadian

$9 / 99$ Men, 1976-1992: Evidence from Longitudinal Income Tax Records

Occupational Gender Composition and Wages in Canada: 9/99 1987-1988

The Adequacy of Life Insurance: Evidence from the $\quad 10 / 99$ Health and Retirement Survey

Is Public R\&D a Complement or Substitute for Private

$10 / 99$ R\&D? A Review of the Econometric Evidence

Do "High Performance" Work Practices Improve $10 / 99$ Established-Level Outcomes?

Was an Industrial Revolution Inevitable? $10 / 99$ Economic Growth Over the Very Long Run Differences of Opinion, Rational Arbitrage and Market Crashes

$10 / 99$

Copies of the above working papers can be obtained for $\$ 10.00$ per copy (plus $\$ 10.00$ per order for shipping for all locations outside the continental U.S.) to Working Papers, NBER, 1050 Massachusetts Avenue, Cambridge, MA 02138-5398. Pre-payment is required on all orders and may be made by check or credit card. Checks should be made payable to the NBER and must be in dollars drawn on a U.S. bank. If paying by credit card, include the cardholder's name, account number, and expiration date. For all orders, please be sure to include your return address and telephone number. Working papers may also be ordered by telephone (868-3900), fax (617-868-2742), or email (orders (a) nber.org).

\section{You can download these and other papers at the NBER Web site: www.nber.org \\ Free searchable abstracts are also available at the site.}

